\title{
Evaluation of a Lagrangian Soot Tracking Method for the prediction of primary soot particle size under engine-like conditions
}

Cai Ong, Jiun ; Pang, Kar Mun; Walther, Jens Honore; Ho, Jee-Hou; Kiat Ng, Hoon

Published in:

Journal of Aerosol Science

Link to article, DOI:

10.1016/j.jaerosci.2017.10.013

Publication date:

2018

Document Version

Peer reviewed version

Link back to DTU Orbit

Citation (APA):

Cai Ong, J., Pang, K. M., Walther, J. H., Ho, J-H., \& Kiat Ng, H. (2018). Evaluation of a Lagrangian Soot Tracking Method for the prediction of primary soot particle size under engine-like conditions. Journal of Aerosol Science, 115, 70-95. https://doi.org/10.1016/j.jaerosci.2017.10.013

\section{General rights}

Copyright and moral rights for the publications made accessible in the public portal are retained by the authors and/or other copyright owners and it is a condition of accessing publications that users recognise and abide by the legal requirements associated with these rights.

- Users may download and print one copy of any publication from the public portal for the purpose of private study or research.

- You may not further distribute the material or use it for any profit-making activity or commercial gain

- You may freely distribute the URL identifying the publication in the public portal 


\section{Author's Accepted Manuscript}

Evaluation of a Lagrangian Soot Tracking Method for the prediction of primary soot particle size under engine-like conditions

Jiun Cai Ong, Kar Mun Pang, Jens Honore Walther, Jee-Hou Ho, Hoon Kiat Ng

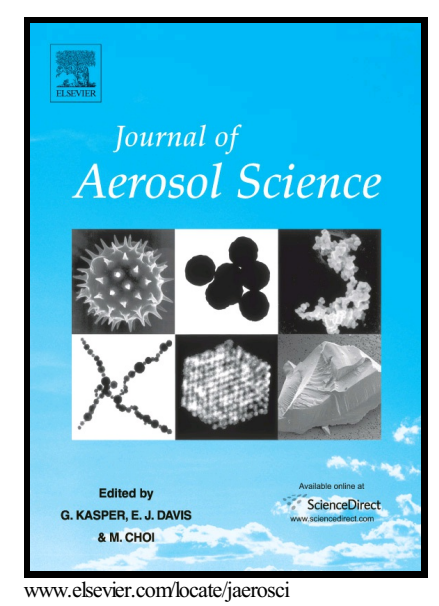

PII:

S0021-8502(17)30162-3

DOI: $\quad$ https://doi.org/10.1016/j.jaerosci.2017.10.013

Reference: AS5212

To appear in: Journal of Aerosol Science

Received date: 2 May 2017

Revised date: 30 October 2017

Accepted date: 30 October 2017

Cite this article as: Jiun Cai Ong, Kar Mun Pang, Jens Honore Walther, Jee-Hou Ho and Hoon Kiat Ng, Evaluation of a Lagrangian Soot Tracking Method for the prediction of primary soot particle size under engine-like conditions, Journal of Aerosol Science, https://doi.org/10.1016/j.jaerosci.2017.10.013

This is a PDF file of an unedited manuscript that has been accepted for publication. As a service to our customers we are providing this early version of the manuscript. The manuscript will undergo copyediting, typesetting, and review of the resulting galley proof before it is published in its final citable form. Please note that during the production process errors may be discovered which could affect the content, and all legal disclaimers that apply to the journal pertain. 


\title{
ACCEPTED MANUSCRIPT
}

\section{Evaluation of a Lagrangian Soot Tracking Method for the prediction of primary soot particle size under engine-like conditions}

\author{
Jiun Cai Ong ${ }^{a}$, Kar Mun Pang ${ }^{b}$, Jens Honore Walther ${ }^{b, c}$, Jee-Hou Ho ${ }^{a}$, Hoon \\ Kiat $\mathrm{Ng}^{a, *}$
}

${ }^{a}$ Department of Mechanical, Materials and Manufacturing Engineering, The University of Nottingham Malaysia Campus, Jalan Broga, 43500 Semenyih, Selangor, Malaysia

${ }^{b}$ Department of Mechanical Engineering, Technical University of Denmark, Nils Koppels Allé, 2800 Kgs. Lyngby, Denmark

${ }^{c}$ Chair of Computational Science, ETH Zürich, Clausiusstrasse 33 ETH-Zentrum, CLT F 11, CH-8092 Zürich, Switzerland

\begin{abstract}
This paper reports the implementation and evaluation of a Lagrangian soot tracking (LST) method for the modelling of soot in diesel engines. The LST model employed here has the tracking capability of a Lagrangian method and the ability to predict primary soot particle sizing. The Moss-Brookes soot model is used here as the Eulerian method to simulate soot formation and oxidation processes. The inception, surface growth and oxidation models are adopted and modified such that the associated reaction rates can be computed using the Lagrangian approach. The soot nuclei are treated as Lagrangian particles when the mass of incipient soot exceeds a designated threshold value. Their trajectories are then computed using the particle momentum equation. The change of primary soot particle size is dependent on the modified Lagrangian surface growth and soot oxidation models. Performance of the LST model in predicting temporal soot cloud development, mean soot diameter and primary soot size distribution is evaluated using measurements of $n$-heptane and $n$-dodecane spray combustion obtained under diesel engine-like conditions. In addition, sensitivity studies are carried out to investigate the influence of soot surface ageing and oxidation rates on the primary soot particle size distribution. With the use of surface ageing, the predicted maximum primary soot particle sizes are closer to the experimentally measured
\end{abstract}

*Corresponding author. Email: hoonkiat.ng@ nottingham.edu.my 


\section{ACCEPTED MANUSCRIPT}

maximum primary soot sizes. Also, the associated particle size distribution shows a lognormal shape. A higher rate of soot oxidation due to $\mathrm{OH}$ causes the soot particles to be fully oxidized downstream of the flame. In general, the LST model performs better than the Eulerian method in terms of predicting soot sizing and accessing information of individual soot particles, both of which are shortcomings of the Eulerian method.

Keywords: soot formation; soot oxidation; primary soot particle size; Lagrangian soot tracking; diesel engine

\section{Nomenclature}

$\mathrm{C}_{\mathrm{D}} \quad$ Drag coefficient (-)

d Diameter $(m)$

$\vec{g} \quad$ Gravitational acceleration $\left(\mathrm{m} / \mathrm{s}^{2}\right)$

k Turbulent kinetic energy $\left(\mathrm{m}^{2} / \mathrm{s}^{2}\right)$

m Mass $(\mathrm{kg})$

M Mass concentration $\left(\mathrm{kg} / \mathrm{m}^{3}\right)$

$\mathrm{M}_{\mathrm{p}} \quad$ Mass of an incipient soot particle $(\mathrm{kg} / \mathrm{kmol})$

$\mathrm{N} \quad$ Number density $\left(1 / \mathrm{m}^{3}\right)$

$\mathrm{N}_{\mathrm{A}} \quad$ Avogadro constant $(1 / \mathrm{mol})$

$\mathrm{N}_{\mathrm{p}} \quad$ Number of Lagrangian particles (-)

$\mathrm{P} \quad$ Pressure $(\mathrm{Pa})$

R Gas constant $\left(\mathrm{kg} \mathrm{m}^{2} / \mathrm{kmol} \mathrm{K} \mathrm{s}^{2}\right)$

Re Reynolds number (-)

$\mathrm{S}_{\text {soot }} \quad$ Soot surface area $\left(\mathrm{m}^{2}\right)$

$\mathrm{T} \quad$ Temperature $(\mathrm{K})$

$\vec{u} \quad$ Fluid velocity (m/s)

$\vec{v} \quad$ Velocity $(\mathrm{m} / \mathrm{s})$

X Mole fraction (-) 


\section{ACCEPTED MANUSCRIPT}

Y Mass fraction (-)

Greek

$\alpha \quad$ Surface ageing factor (-)

$\varepsilon \quad$ Turbulent dissipation rate $\left(\mathrm{m}^{2} / \mathrm{s}^{3}\right)$

$\rho \quad$ Density $\left(\mathrm{kg} / \mathrm{m}^{3}\right)$

$\eta_{\text {coll }}$ Collision efficiency parameter (-)

Subscripts

avg Average

am Ambient condition

inc Inception process

ox Oxidation process

$\mathrm{p} \quad$ Lagrangian soot particle

prec Soot precursor

sg Surface growth process

soot Soot particles

\section{Introduction}

In-cylinder and engine-out diesel soot production has been widely studied numerically using various soot models. The soot models can be classified as full empirical correlations (Hiroyasu, Kadota, \& Arai, 1983; Khan, Greeves, \& Probert, 1971), semi-empirical correlations (Fairweather, Jones, \& Lindstedt, 1992; Moss, Stewart, \& Young, 1995) and detailed soot models (Franken \& Mauss, 2016; Frenklach, 2002a, 2002b; Frenklach \& Wang, 1991; Pasternak, Mauss, \& Bensler, 2009; Tunér, Pasternak, Mauß, \& Bensler, 2008; Wang et al., 2016; Q. Zhang, Guo, Liu, Smallwood, \& Thomson, 2009). In general, full empirical soot models are relatively simple and computationally affordable to be used in conjunction 


\section{ACCEPTED MANUSCRIPT}

with multidimensional computational fluid dynamics (CFD) model. While they are mainly designed for the prediction of engine-out soot concentration, their performance in the prediction of in-cylinder soot production has yet to be widely assessed. In contrast, detailed soot models contain the full panoply of soot phenomena, i.e. the initial pyrolysis of fuel, the formation of large polycyclic aromatic hydrocarbon (PAH), the inception of soot particles, surface growth, PAH condensation, coagulation and oxidation. However, such comprehensive models impose a heavy computational cost. This limits their broad application in CFD simulations and industrial-level design of diesel engines. Meanwhile, semi-empirical models only consider the essential soot formation processes and generally allow the use of skeletal chemical mechanisms. Hence, they provide a good compromise between detailed simulation results and computational costs. To date, they have been widely used in CFD studies of soot formation under engine-like conditions (Pang, Jangi, Bai, \& Schramm, 2015; Pang, Ng, \& Gan, 2012a, 2012b, Tan, Ng, \& Gan, 2013a, 2013b). Detailed descriptions of the aforementioned soot models can be found in the review study by Omidvarborna et al. (2015).

Disregarding the type of soot modeling approach, one of the challenges faced is to simulate the soot particle dynamics, such as tracking the primary soot particle size, soot aggregate size and soot aggregate structure of the soot particles that are formed. In terms of soot particle size, a relatively simple approach to predict the average value is by using the semi-empirical, two equation soot model without tracking the soot particle distribution (Fairweather et al., 1992). With this method, all the soot particles are assumed to be spherical with identical diameters within a control volume (i.e. mono-dispersed spherical particle). The predicted average soot particle size via the semi-empirical soot model is estimated on a cellby-cell basis where the characteristic diameter of the particles $d_{s o o t, j}$ in the computational 


\section{ACCEPTED MANUSCRIPT}

cell $j$, is computed based on the associated soot mass concentration, $M_{\text {soot }}$ and soot particle number density, $N_{\text {soot }}$ using

$d_{\text {soot }, j}=\left(\frac{6 M_{\text {soot }, j}}{\pi \rho_{\text {soot }} N_{\text {soot }, j}}\right)^{1 / 3}$

where $\rho_{\text {soot }}$ is the soot density. However, it is important to note that in the calculation of the average particle size, the sizes of the primary soot particles (Fig. 1) and the soot aggregates cannot be differentiated. In the formation of diesel soot, the size of the primary soot particles is influenced by engine operating parameters such as variation in air to fuel ratio (Lapuerta, Martos, \& Herreros, 2007), engine speed, load (Kock, Tribalet, Schulz, \& Roth, 2006; Menkiel, Donkerbroek, Uitz, Cracknell, \& Ganippa, 2012) and fuel injection pressure (Ryser, Gerber, \& Dreier, 2009). Thus, an understanding of the factors affecting the primary soot particle size would lead to a more effective way in reducing its size, and ultimately, reducing the total amount of soot formed in engine applications. Furthermore, this understanding can also lead to a deeper insight into the formation of soot aggregates.

There are currently a few promising methods for modeling the soot particle dynamics and primary soot particle size. One approach is by using the Method of Moments (MOM) (Frenklach, 2002a), in which the evolution equations for moments of the population distribution are solved instead of explicitly solving the population distribution (Mueller, Blanquart, \& Pitsch, 2009). Its computational efficiency enables it to be applicable in complex problems such as soot formation in diesel applications (Ito, Hosaka, Ueda, Senda, \& Fujimoto, 2004; Karlsson, Magnusson, Balthasar, \& Mauss, 1998; Naik, Puduppakkam, \& Meeks, 2014; Priesching et al., 2005; Y.-N. Song \& Zhong, 2008). However, as it only predicts the ensemble averaged quantities, the exact shape of the particle size distribution is unknown. Another approach which is easy to implement and provides detailed particle size 


\section{ACCEPTED MANUSCRIPT}

distribution is the discrete sectional method (DSM) (Gelbard \& Seinfeld, 1980; Gelbard, Tambour, \& Seinfeld, 1980; C. J. Pope \& Howard, 1997). In this method, the population of soot particles is discretized into discrete sections or "bins", and the evolution equations are solved for each of these bins. A good accuracy is achieved when an adequate number of sections is used to represent the particle size distribution. However, it is computationally expensive as the shape of soot particles is described by more than one size property (Salenbauch et al., 2015). It is also noteworthy that both MOM and DSM can only provide the mean primary particle soot size, and do not provide information about the history of the soot particles.

Monitoring the history of individual soot particles is nonetheless essential. Such information is expected to provide a better understanding of the formation, growth and oxidation of soot particles since the morphology of soot is shown to be dependent on fuel type or composition (Aizawa, Takahata, Okabe, \& Mizutani, 2015; Merchan-Merchan, Sanmiguel, \& McCollam, 2012; Savic et al., 2016; J. Song \& Lee, 2007) and operating conditions (Hadavi et al., 2012; Kuribayashi, Mizutani, Ishizuka, Taki, \& Aizawa, 2014; Lapuerta, Ballesteros, \& Martos, 2009; Lu, Cheung, \& Huang, 2012; Vishwanathan \& Reitz, 2015; R. Zhang \& Kook, 2014; Zhu, Lee, Yozgatligil, \& Choi, 2005). The results obtained are the cumulative effect of all the individual soot particles interacting with one another and their surrounding environment (e.g. ambient conditions and gas-phase compositions) within the flame. The stochastic approach, in which the population of particles is determined by using a stochastic algorithm such as the Monte-Carlo method can be applied for such detailed soot dynamics study. The Monte-Carlo stochastic approach (Balthasar \& Kraft, 2003; J. Singh, Balthasar, Kraft, \& Wagner, 2005; Zhao et al., 2003) tracks a statistically significant number of soot particles individually, and has the potential to provide a detailed representation of particle size distribution function (PSDF) including primary soot size 


\section{ACCEPTED MANUSCRIPT}

distribution, number density of primary soot size, aggregate size, etc. Nevertheless, this

model is computationally expensive and is often limited to post-processing of data than being fully integrated with the CFD flow solver (Roy et al., 2014). Thus, it is imperative to develop a method which can study the individual soot particles and yet is computationally feasible for diesel engine applications.

Alternatively, the Lagrangian soot tracking (LST) method can be used to analyze the history and individual information of the soot particles. In the LST framework, the soot particles are treated as Lagrangian particles and can be tracked individually. The LST method has been used to investigate soot transport in various combustion applications (Fuentes et al., 2007; V R Katta et al., 2011; Viswanath R Katta, Blevins, \& Roquemore, 2005; Mahmood, LaRocca, Shayler, Bonatesta, \& Pegg, 2012; F Piscaglia, Onorati, Rutland, \& Foster, 2009; Federico Piscaglia, Rutland, \& Foster, 2005; P. Zhang, Roberts, \& Benard, 2012; Zuber et al., 2015). Katta et al. (2005) performed a CFD-detailed chemical kinetics study of an ethyleneair inverse diffusion flame. In their study, Lagrangian soot particles of 20nm were released into the domain along the $1200 \mathrm{~K}$ contour line with the assumption that soot inception occurs at $1200 \mathrm{~K}$. A similar study was carried out by Fuentes et al. (2007) who tracked the history of 50nm diameter soot particles from inception to oxidation zone along their simulated trajectories in a non-buoyant laminar diffusion flame. It is worth mentioning that these works did not include oxidation effects on their Lagrangian soot particles. In a later study, the soot tracking model (Katta et al., 2011; Roquemore et al., 2009) was improved by considering the effect of soot oxidation. A soot burnout model was introduced such that the fictitious soot particles were deleted when they entered temperature regions above $1300 \mathrm{~K}$ (Roquemore et al., 2009) or above 1400K (Katta et al., 2011).

To the authors' best knowledge, while the LST models have been used to study different laminar flames, evaluations of the LST models for diesel engine combustion 


\section{ACCEPTED MANUSCRIPT}

applications are limited. Numerical works which are closer to such applications were carried out by Mahmood et al. (2012) and Zuber et al. (2015), who developed an LST model which used a tri-linear interpolation technique to obtain the soot particle trajectories and also the soot particle size evolution along the soot particle path in diesel engine cases. Soot trajectories were traced from selected starting points in the engine cylinder based on soot concentration distribution from the numerical simulation. The soot formation process was predicted based on Hiroyasu's soot formation model (Hiroyasu et al., 1983). On the other hand, the soot oxidation rates due to oxygen $\left(\mathrm{O}_{2}\right)$ and hydroxyl $(\mathrm{OH})$ were calculated based on the Nagle and Strickland-Constable (NSC) (Nagle \& Strickland-Constable, 1962) and the Neoh models (Neoh, Howard, \& Sarofim, 1985), respectively. Simple chemistry was used to simulate the fuel oxidation and combustion processes. Chemical equilibrium or partial equilibrium assumptions were applied to estimate the formation of $\mathrm{OH}$. However, $\mathrm{OH}$ can be formed in quantities well over the equilibrium values in the flame zone and thus calculation of super-equilibrium radical concentrations becomes complex. Integration with fuel oxidation kinetics is hence preferred in this case (Turns, 2012). Also, the soot model constants used in the above works were calibrated based on engine-out soot emissions. This does not guarantee that the in-cylinder soot mass and hence diameter are correctly estimated.

Set against this background, the core objective of this work is to develop an LST model that is based on a semi-empirical soot model for diesel engine applications. Skeletal chemical mechanisms are used in this framework. The performance of the proposed model is evaluated based on the experimental temporal/spatial soot cloud distribution and primary soot particle size distribution. In addition to this, the sensitivity of the model with respect to different soot processes is also investigated. The paper is structured such that the numerical formulation and setup are first provided, with an emphasis on the LST model. This is followed by the validation of CFD models using non-reacting and reacting spray 


\section{ACCEPTED MANUSCRIPT}

experimental data. Next, the evaluation of the proposed LST model in predicting primary soot size is carried out. Sensitivity studies are subsequently carried out to investigate the influence of soot surface ageing and oxidation rate on the primary soot sizing prediction. The final section highlights key conclusions of the present paper.

\section{Numerical formulation and setup}

\subsection{Mesh and model setup}

In this work, the CFD simulations are carried out using the spray combustion solver in the open-source code, OpenFOAM version 2.0.x (Weller, Tabor, Jasak, \& Fureby, 1998). Experimental data from two different constant volume combustion vessels are used for the present model validation. The first set of data are the measurements of the $n$-heptane spray combustion obtained from the Doshisha combustion vessel (Ito et al., 2004) while the second data set are the $n$-dodecane spray combustion measurements from the Sandia combustion vessel (ECN, 2010). They are henceforth addressed as the Doshisha $n$-heptane case and the Sandia $n$-dodecane case, respectively for brevity.

Both the constant volume combustion vessels are represented by a cylinder in the simulation studies. For computational expediency, the cylindrical chamber is simplified to a 4-degree axisymmetric wedge with a single layer of cells in the tangential direction. The diameter and height of the cylinder are adjusted such that the total volume of the cylinder is the same as the actual combustion chamber. For the Doshisha $n$-heptane case, a radius of $30 \mathrm{~mm}$ and a height of $120 \mathrm{~mm}$ are used which correspond to the dimensions provided in the literature (Ito et al., 2004). As for the Sandia $n$-dodecane case, the radius and height of the cylinder are set to $54 \mathrm{~mm}$ and $138 \mathrm{~mm}$, respectively. A sample mesh is shown in Fig. 2. Mesh independence is achieved using a cell size of $0.50 \mathrm{~mm}$ for both radial $(r)$ and axial $(x)$ directions within the spray combustion region. The same mesh resolutions are used 


\section{ACCEPTED MANUSCRIPT}

throughout all the test cases. Further discussion about the mesh independence study can be found in Section 4.1.1. The time step size is fixed at $0.1 \mu$ s for both the Doshisha $n$-heptane and Sandia $n$-dodecane test cases. The Doshisha $n$-heptane simulation is carried out at ambient $\mathrm{O}_{2}$ concentration of $21 \%$. The ambient gas density is set to $16.2 \mathrm{~kg} / \mathrm{m}^{3}$ while the ambient temperature is fixed at $900 \mathrm{~K}$. As for the Sandia $n$-dodecane case, the numerical studies are carried out at ambient $\mathrm{O}_{2}$ levels of $15 \%$ and $21 \%$, where both cases have an ambient density of $22.8 \mathrm{~kg} / \mathrm{m}^{3}$ and an ambient temperature of $900 \mathrm{~K}$. Injection specifications and profiles in the current simulations are set to correspond to those in the experimental setup. The details of the experimental conditions including the injection profiles are shown in Table 1.

Table 1: Experimental conditions for three different test cases (ECN, 2010; Ito et al., 2004).

\begin{tabular}{llllllll}
\hline Case name & $\begin{array}{l}T_{a m} \\
{[\mathrm{~K}]}\end{array}$ & $\begin{array}{l}\rho_{a m} \\
{\left[\mathrm{~kg} / \mathrm{m}^{3}\right]}\end{array}$ & $\begin{array}{l}\mathrm{O}_{2} \% \\
{[-]}\end{array}$ & $\begin{array}{l}\text { Injection } \\
\text { duration } \\
{[\mathrm{ms}]}\end{array}$ & $\begin{array}{l}\text { Nozzle } \\
\text { orifice } \\
\text { diameter } \\
{[\mathrm{mm}]}\end{array}$ & $\begin{array}{l}\text { Injection } \\
\text { pressure } \\
\text { drop } \\
{[\mathrm{MPa}]}\end{array}$ & $\begin{array}{l}\text { Total fuel } \\
\text { mass }[\mathrm{mg}]\end{array}$ \\
\hline Doshisha $n$-heptane & 900 & 16.2 & 21 & 2.65 & 0.20 & 70 & 19.0 \\
Sandia $n$-dodecane & 900 & 22.8 & $\begin{array}{l}15 \\
21\end{array}$ & 6.0 & 0.09 & 150 & 13.77 \\
\hline
\end{tabular}

$T_{a m}$ : Ambient temperature ; $\rho_{a m}$ : Ambient density ; $\mathrm{O}_{2} \%$ : Ambient oxygen concentration (in mole fraction)

\subsection{Spray-turbulence-chemistry formulation}

The unsteady Reynolds-averaged simulations (URANS) are used in this work. A finitevolume method is utilized to solve the transport equations for mean quantities using a pressure-based, segregated, iterative, time-implicit method (PISO-based (Issa, 1986)). The discretization is second-order with respect to space and first-order with respect to time. The turbulence is modeled using the standard $k-\varepsilon$ model. The model constant $C_{1 \varepsilon}$ is a constant for the rate of production of turbulent dissipation, $\varepsilon$ in the standard $k-\varepsilon$ model. For the Sandia $n$-dodecane case, the $C_{1 \varepsilon}$ value is calibrated from the default 1.44 (Janicka $\&$ Peters, 


\section{ACCEPTED MANUSCRIPT}

1982; S. B. Pope, 1979) to 1.58. It is common practice in diesel spray simulation (Skeen et al., 2016) to correct the round-jet anomaly (Novella, García, Pastor, \& Domenech, 2011; Pang, Jangi, Bai, \& Schramm, 2014) which otherwise leads to an underestimation of the penetration length. It is important to mention that the default $C_{1 \varepsilon}$ constant value of 1.44 is used for the Doshisha $n$-heptane case due to the absence of non-reacting experimental data from the literature for the model calibration.

The initial turbulence kinetic energy, $k$ is set at $0.735 \mathrm{~m}^{2} / \mathrm{s}^{2}$ while the initial turbulence dissipation rate, $\varepsilon$ is set at $3.83 \mathrm{~m}^{2} / \mathrm{s}^{3}$ for the Sandia $n$-dodecane case (Bhattacharjee $\&$ Haworth, 2013). The initial values of $\varepsilon$ and $k$ are calculated using

$\varepsilon=C_{\mu}^{0.75} k^{1.5} / l_{T}$

$k=1.5 U_{r m s}^{2}$

where $l_{T}=0.024 \mathrm{~m}$ is the initial turbulence length scale (assumed to be half of the domain radius) and $U_{r m s}$ is the mean swirl velocity which is taken to be $0.7 \mathrm{~m} / \mathrm{s}$. As preliminary studies have shown that the initial turbulence conditions have insignificant effects on spray and combustion characteristics, similar initial turbulence conditions are used for the Doshisha case. The initial mean flow field velocities for all cases are set to zero.

The conventional Eulerian-Lagrangian approach for spray modeling is employed here, which means that the Lagrangian approach is used for the liquid phase and the Eulerian approach for the gas phase. The fuel injection and spray evolution are modeled using a stochastic Lagrangian parcel method (Dukowicz, 1980). In this method, the spray is represented by a finite number of parcels. Both liquid and gas phases are coupled by introducing source terms in the mass, species, momentum and energy transport equations. 


\section{ACCEPTED MANUSCRIPT}

Fuel injection is modeled using standard practice for high-pressure diesel sprays, where no explicit primary breakup model is used (Bhattacharjee \& Haworth, 2013). Instead, constantdiameter "blobs" are injected at the fuel-injector orifice location, where the initial droplet diameter is estimated based on the nozzle orifice diameter and contraction coefficient. The initial velocity of the "blobs" is estimated based on the pressure drop across the injector. The spray breakup is described using the Reitz-Diwakar model (Reitz \& Diwakar, 1986). The spray constant, $C_{S}$ is the time factor constant for stripping breakup in which the liquid is sheared or stripped from the droplet surface. An increase in $C_{S}$ means that the characteristic time scale of the breakup process is increased, consequently reducing the breakup rate. The $C_{s}$ values are fixed at 10 and 10.5 in the Doshisha $n$-heptane and the Sandia $n$-dodecane test cases, respectively. Collision and coalescence with the fuel spray region are omitted in all studies as these processes have negligible influence on the liquid and vapor fuel penetration of the evaporating spray (Jangi, D’Errico, Bai, \& Lucchini, 2012). In addition, the RanzMarshall correlation (Ranz \& Marshall, 1952) is implemented to calculate the droplet heat transfer with the surrounding gas phase while the Frossling correlation (Frossling, 1956) is used to calculate the evaporation of the fuel droplet. The details of the spray models such as the governing equations and the spray sub-models can be found in (Stiesch, 2013).

For the Doshisha $n$-heptane test case, the skeletal $n$-heptane model developed by Pang et al. (2011) is implemented. It comprises 46 species and 112 reactions that are essential to diesel ignition, combustion and soot precursor formation. In contrast, the skeletal mechanism for $n$-dodecane developed by Luo et al. (2014) is used for the Sandia test case. The mechanism composes of 106 species and 420 reactions. Further details on these mechanisms can be found in (Pang et al., 2011) and (Luo et al., 2014), respectively. The well-stirred reactor (WSR) model is implemented in which the sub-grid turbulence-chemistry interaction (TCI) effects are not considered. It should be mentioned that, in general, considering a TCI 


\section{ACCEPTED MANUSCRIPT}

closure approach improves the prediction of ignition delay (ID) time and lift-off length (LOL), particularly for low ambient $\mathrm{O}_{2}$ and temperature levels (Bhattacharjee \& Haworth, 2013). However, a comprehensive TCI closure approach such as the transported probability density function (TPDF) model is computationally expensive. Since the main focus in this study is to evaluate the performance of the Lagrangian soot model, the computationally efficient WSR which is also widely used for spray combustion modelling is selected (Cheng, Ng, Gan, Ho, \& Pang, 2015; D’Errico, Lucchini, Contino, Jangi, \& Bai, 2014; Pang, Jangi, et al., 2015; Poon, Pang, Ng, Gan, \& Schramm, 2016). As explained later in Section 3.2, the model is able to predict the ID of the Doshisha case while the variations of ID and LOL with respect to the change in $\mathrm{O}_{2}$ level in the Sandia $n$-dodecane cases are reproduced. This allows the evaluation of the Lagrangian soot model in these cases.

\subsection{Multi-step soot model}

In this study, the spray combustion solver is incorporated with the semi-empirical, multi-step Moss-Brookes (MB) soot model (Brookes \& Moss, 1999) which is provided by a soot library constructed in a previous work (Pang, Jangi, et al., 2015). The selected soot model is computed via an Eulerian method, and accounts for soot inception (inc), surface growth ( $s g$ ), coagulation (coag) and oxidation (ox) due to $\mathrm{O}_{2} / \mathrm{OH}$. Acetylene $\left(\mathrm{C}_{2} \mathrm{H}_{2}\right)$ is chosen as the soot precursor and surface growth species in the MB soot model. Production rates of $\mathrm{C}_{2} \mathrm{H}_{2}, \mathrm{O}_{2}$ and $\mathrm{OH}$ are first calculated based on the gas-phase reactions, and the resulting concentrations are used in the governing equations of the multi-step soot model, i.e. the transport equations for the soot mass fraction, $Y_{\text {soot }}$, and the normalized radical nuclei concentration, $b_{n u c}^{*}$. The source term for the $Y_{\text {soot }}$ transport equation denotes the net soot mass production and is modeled according to the expression 
$\frac{d M_{\text {soot }}}{d t}=M_{p} \omega_{i n c}+\omega_{s g}-\omega_{o x}$

where $M_{\text {soot }}=\rho Y_{\text {soot }}$ and $\rho$ is the fluid density. The terms on the right-hand side (RHS) of Eq. (4) are the reaction rates for inception, surface growth and oxidation processes, respectively. The associated reaction rates are calculated as below:

$\omega_{\text {inc }}=C_{\text {inc }}\left(\frac{X_{\text {prec }} P}{R T}\right) \exp \left\{-\frac{T_{\text {inc }}}{T}\right\}$

$\omega_{s g}=\alpha C_{s g}\left(\frac{X_{s g} P}{R T}\right) \exp \left\{-\frac{T_{s g}}{T}\right\} S_{\text {soot }}$

$\omega_{\text {ox }}=C_{O H} \eta_{\text {coll }}\left(\frac{X_{O H} P}{R T}\right) \sqrt{T} S_{\text {soot }}+C_{O_{2}}\left(\frac{X_{O_{2}} P}{R T}\right) \exp \left\{-\frac{T_{O_{2}}}{T}\right\} \sqrt{T} S_{\text {soot }}$

Here, $X_{\text {prec }}$ and $X_{s g}$ denote the mole fractions of soot precursor and participating surface growth species, respectively. The mole fractions of soot oxidants, $\mathrm{OH}$ and $\mathrm{O}_{2}$, are represented by $X_{O H}$ and $X_{O_{2}}$, respectively. $S_{\text {soot }}$ denotes the specific surface area. $T, P$ and $R$ represent the gas temperature, pressure and universal gas constant, respectively. The constant $M_{P}$ represents the mass of an incipient soot particle which is set to $1200 \mathrm{~kg} / \mathrm{kmol}$. The soot model constants, their descriptions, default model constant values and the associated references are compiled in Table 2. The $\alpha$ in Eq. (6) denotes the surface ageing factor, which has been added into the default MB soot model to take into account the surface ageing effect. This modification is carried out as it has been observed experimentally that the surface growth rate is highly dependent on the soot surface reactivity (Harris \& Weiner, 1985; Brian S Haynes \& Wagner, 1981). Therefore, a surface ageing model which correlates to the flame temperature, as proposed by Kazakov et al. (1995), is implemented in the current work. The expression for $\alpha$ is given as

$\alpha=\frac{1}{2}\left(\tanh \left(\frac{8168}{T}-4.57\right)+1\right)$ 


\section{ACCEPTED MANUSCRIPT}

This surface ageing model was successfully implemented in diesel spray numerical studies by

Kaminaga et al. (2008) and Tao et al. (2004).

Table 2: Soot model constants with their respective descriptions and default values ("ANSYS FLUENT 16.2 User's Guide,” 2015; Brookes \& Moss, 1999).

\begin{tabular}{cll}
\hline Soot Model Constants & Descriptions & Value [Unit] \\
\hline$C_{i n c}$ & Model constant for incipient rate & $54\left[\mathrm{~s}^{-1}\right]$ \\
$C_{s g}$ & Surface growth rate scaling factor & $11700\left[\mathrm{~kg} \mathrm{~m} \mathrm{kmol}^{-1} \mathrm{~s}^{-1}\right]$ \\
$C_{O H}$ & Model constant for oxidation due to $\mathrm{OH}$ & $105.81\left[\mathrm{~kg} \mathrm{~m} \mathrm{kmol}^{-1} \mathrm{~K}^{-0.5} \mathrm{~s}^{-1}\right]$ \\
$C_{O_{2}}$ & Model constant for oxidation due to $\mathrm{O}_{2}$ & $8903.51\left[\mathrm{~kg} \mathrm{~m} \mathrm{kmol}^{-1} \mathrm{~K}^{-0.5} \mathrm{~s}^{-1}\right]$ \\
$T_{i n c}$ & Activation temperature of inception & $21000[\mathrm{~K}]$ \\
$T_{s g}$ & Activation temperature of surface growth & $12100[\mathrm{~K}]$ \\
$T_{O_{2}}$ & Activation temperature of oxidation due to $\mathrm{O}_{2}$ & $19778[\mathrm{~K}]$ \\
$\eta_{c o l l}$ & Collision efficiency parameter & $0.04[-]$ \\
\hline
\end{tabular}

The source term of the $b_{n u c}^{*}$ transport equation is the instantaneous production rate of soot particles, which is subjected to inception from the gas phase and coagulation in the free molecular regime, and is computed using

$\frac{d N_{\text {soot }}}{d t}=N_{A} \omega_{\text {inc }}-\omega_{\text {coag }}$

The first term on the RHS of Eq. (9) is the product of the Avogadro constant, $N_{A}$, and the inception rate, $\omega_{\text {inc }}$, as introduced in Eq. (5), while the second term is a sink term due to coagulation, $\omega_{\text {coag. }}$. The second term on the RHS of Eq. (9) is described by

$\omega_{\text {coag }}=C_{\text {coag }}\left(\frac{24 R T}{\rho_{\text {soot }} N_{A}}\right)^{1 / 2}\left(\frac{6 M_{\text {soot }}}{\pi \rho_{\text {soot }}}\right)^{1 / 6} N_{\text {soot }}^{11 / 6}$

where the model constant value, $C_{\text {coag }}$, in Eq (10) is set as 1.0 .

\subsection{Lagrangian soot tracking formulation}

\subsubsection{Lagrangian method for soot particles}

In the LST model, the soot particles are tracked via the Lagrangian method, in which the soot 


\section{ACCEPTED MANUSCRIPT}

particles in the airflow can encounter inertia and hydrodynamic drag. Due to these experienced forces in the flow field, the particles can either be accelerated or decelerated. The soot particle velocity change can be formulated by

$m_{p} \frac{d \overrightarrow{\mathrm{v}}_{\mathrm{p}}}{d t}=-\rho \frac{\pi d_{p}^{2}}{8} C_{D}\left(\overrightarrow{\mathrm{v}}_{\mathrm{p}}-\vec{u}\right)\left|\overrightarrow{\mathrm{v}}_{\mathrm{p}}-\vec{u}\right|+\frac{m_{p} \overrightarrow{\mathrm{g}}\left(\rho_{p}-\rho\right)}{\rho_{p}}$

It is important to note that no particle-particle interaction is considered as it is only dominant during the coagulation process (Bockhorn, 2009; Maraver, 2015) which is not considered in this work. Further explanation regarding the absence of the coagulation process can be found in Section 2.3.2. A forward Euler method is applied to the time derivatives in Eq. (11) and all the subsequent time derivatives involved in the LST model. The first term on the RHS of Eq. (11) represents the drag force experienced by the Lagrangian particles. The equation for drag coefficient, $C_{D}$ is

$C_{D}= \begin{cases}\frac{24}{R e_{p}}\left(1+\frac{R e_{p}^{\frac{2}{3}}}{6}\right) & R e_{p}<1000 \\ 0.44 & R e_{p}>1000\end{cases}$

where it is dependent on the particle Reynolds number, $R e_{p}=\frac{\rho d_{p}\left|\vec{v}_{\mathrm{p}}-\vec{u}\right|}{\mu}$ (Schiller \& Naumann, 1935). The second term on the RHS of Eq. (11) represents the gravitational force and buoyancy force whereby $\rho_{p}$ is the density of particle. $m_{p}$ and $\vec{v}_{\mathrm{p}}$ denote the particle mass and velocity, respectively.

The fluid velocity $\vec{u}$ can be decomposed into two components, the mean fluid velocity $\overrightarrow{\vec{u}}$ and the fluctuating component $u^{\prime}$. The trajectories of the particles follow the mean fluid velocity $\overrightarrow{\vec{u}}$ while the dispersion of particles due to turbulence is influenced by the 


\section{ACCEPTED MANUSCRIPT}

instantaneous fluctuating velocity $u^{\prime}$ (Kitanidis, 1994; Z. Zhang \& Chen, 2007). In this study, $u^{\prime}$ is modeled by applying the discrete random walk model (DRW) (Kitanidis, 1994; Z. Zhang \& Chen, 2007). It correlates with the flow turbulent kinetic energy $k$, predicted by the standard $k-\varepsilon$ model, and is expressed by

$u^{\prime}=\zeta \sqrt{2 k / 3}\left\{\begin{array}{l}1 \\ 1 \\ 1\end{array}\right\}$

where $\zeta$ is a Gaussian random number (Kitanidis, 1994; Z. Zhang \& Chen, 2007) with zero mean and unit variance.

\subsubsection{Reaction rates for Lagrangian soot particles}

The current work focuses on tracking the primary soot particles and their subsequent evolution. The proposed LST model is simplified such that it considers the soot inception, surface growth and oxidation phenomena while the coagulation process is not taken into account. The coagulation process can be classified as coalescent growth and agglomeration into fractal aggregates (Frenklach, 2002b). The former process involves the collision of small existing particles with newly formed particles to form larger spherical particles (Dobbins, Fletcher, \& Lu, 1995). However, it has been observed that not all collisions result in merging or sticking of particles (D’Alessio, Barone, Cau, D’Anna, \& Minutolo, 2005; Kellerer, Koch, \& Wittig, 2000). Mitchell \& Frenklach (1998) who used the time-dependent Monte-Carlo method to study soot particle growth showed that the surface growth process is an important factor in affecting the level of particle sphericity. It was demonstrated that coagulation alone was insufficient to construct a spheroidal particle without the presence of surface growth (Mitchell \& Frenklach, 1998). In addition to this, a more recent numerical simulation work by Saffaripour et al. (2014) who carried out detailed modeling of soot aggregate formation in 


\section{ACCEPTED MANUSCRIPT}

laminar co-flow diffusion flames by implementing coalescence sub-models, suggested that the coalescent growth process might be less significant. Their results showed that the coalescence process was too slow to account for the growth of primary particles as it was limited by the rate of particle collisions (Saffaripour et al., 2014). The argument of omitting the coagulation model is further supported by a recent study carried out by Akridis \& Rigopoulos (2016) who showed reasonable prediction of the average primary soot particle size in laminar diffusion flame despite neglecting the coagulation mechanism. Conversely, the agglomeration process mainly affects the overall soot number, but not the mass addition onto the soot particle surface. Instead, the size of the primary soot particles is more significantly affected by the surface growth process (Bolla, Wright, Boulouchos, Borghesi, \& Mastorakos, 2013; B S Haynes \& Wagner, 1982). Based on these arguments, the proposed LST model assumes that the coagulation process is relatively insignificant to the primary soot particle size and hence it is neglected. The expressions for inception, surface growth and oxidation rates are adopted from the MB model and implemented in the LST model. The details of the proposed LST model are discussed in the following sections.

\subsubsection{Inception model}

Various approaches have been proposed for the CFD simulations of Lagrangian soot particle formation. In the studies by Piscaglia et al. (2009) and Piscaglia et al. (2005), the position and velocity of the soot particles are pre-defined and placed in the computational domain before the start of the simulation. In other studies (Mahmood et al., 2012; Zuber et al., 2015), the tracking of soot is carried out from selected starting points depending on the soot concentration. In the current proposed LST model, instead of pre-defining the locations and velocities of the particles, Lagrangian particles are formed when a formation criterion in a computational cell is met. The formation criterion in a particular computational cell is that the 


\section{ACCEPTED MANUSCRIPT}

calculated total incipient soot mass in that cell has to be larger than the minimum mass of

incipient soot, which is $2.0 \times 10^{-24} \mathrm{~kg}$. The minimum mass is calculated based on the assumption that the minimum diameter of an incipient soot is $1.24 \mathrm{~nm}$ (Leung, Lindstedt, \& Jones, 1991), with a soot density of $2000 \mathrm{~kg} / \mathrm{m}^{3}$ (Leung et al., 1991; Vishwanathan \& Reitz, 2010). The assumed minimum particle inception size is consistent with the size of circumpyrene or circumcorenene, which is experimentally shown to be responsible for soot nucleation (Adkins \& Miller, 2015; Botero, Adkins, González-Calera, Miller, \& Kraft, 2016; Herdman, Connelly, Smooke, Long, \& Miller, 2011). Since the chemical mechanisms used in the current work do not consider large PAH formation, the inception rate expression based on $\mathrm{C}_{2} \mathrm{H}_{2}$ as given by Eq. (5) is used to estimate the incipient soot mass. The method of initializing Lagrangian particle in the computational cell which meets the formation criterion is further elaborated in Section 2.4.

\subsubsection{Surface growth model}

The newly formed Lagrangian particles then undergo mass addition and increase in size through the surface growth process which is governed by Eq. (6), whereby $\mathrm{C}_{2} \mathrm{H}_{2}$ is selected as the surface growth species. Fig. 3 shows a computational cell with $N_{p}$ number of soot particles with different diameters ranging from $d_{1}$ to $d_{N_{p}}$. As mentioned in Section 1.0, the soot diameter calculated using the Eulerian method which assumes that all the soot inside a computational cell is mono-dispersed (Fairweather et al., 1992). This implies that all the particles in a computational cell have uniform sizes equal to that of the average diameter of all the particles available in the cell, denoted by $d_{\text {avg }}$.

The rate of mass addition via surface growth is dependent on the specific surface area, $S_{\text {soot }}$ of the available soot particles in a computational cell. The specific surface area is calculated by summing up all the available individual soot particles in the computational cell, 


\section{ACCEPTED MANUSCRIPT}

i.e. $S_{\text {soot }}=\sum_{i=1}^{N_{p}} \pi d_{i}^{2}$, where $d_{i}$ is the individual soot diameter. As all the soot particles have the same size as the average diameter based on the mono-dispersed assumption, the specific surface area is simply the product of the total number of soot particles and average soot surface area, $S_{\text {soot }}=N_{p} \pi d_{\text {avg }}^{2}$.

In the proposed LST model, the poly-dispersed assumption is taken into account. This implies that all the soot particles in a computational cell as shown in Fig. 3 have their own distinct, individual diameters. The individual soot surface growth model, $\omega_{s g, i}$ is given as

$\omega_{s g, i}=\left.\frac{d m_{i}}{d t}\right|_{\text {added mass }, i}=f\left(X_{s g}, T, P\right)\left[\pi d_{i}^{2}\right]$

where $f\left(X_{s g}, T, P\right)=\alpha C_{s g}\left(\frac{X_{s g} P}{R T}\right) \exp \left\{-\frac{T_{\gamma}}{T}\right\}$. The rate of change of diameter can be derived from the individual soot surface growth model $\omega_{s g, i}$, by combining Eq. (14) and the mass of an individual soot, denoted as $m_{i}$ which is given below:

$m_{i}=\frac{\pi}{6} d_{i}^{3} \rho_{\text {soot }}$

where $\rho_{\text {soot }}$ is the density of soot while assuming spherical soot particles. Differentiating Eq. (15) with respect to time and equating it to Eq. (14) leads to

$\frac{d}{d t}\left(\frac{\pi}{6} d_{i}^{3} \rho_{\text {soot }}\right)=\frac{d m_{i}}{d t}$

$\frac{\pi d_{i}^{2} \rho_{\text {soot }}}{2} \frac{d}{d t}\left(d_{i}\right)=f\left(X_{s g}, T, P\right)\left[\pi d_{i}^{2}\right]$

$\frac{d}{d t}\left(d_{i}\right)=\frac{2 f\left(X_{s g}, T, P\right)}{\rho_{\text {soot }}}$

Eq. (18) shows that the rate of change in soot diameter is only dependent on the temperature, pressure and mole fraction of the surface growth species of that particular computational cell. Finally, the rate of change of diameter of Lagrangian particle (by surface growth) is written as 


$$
\left.\frac{d}{d t}\left(d_{i}\right)\right|_{S G}=2 \alpha C_{s g}\left(\frac{X_{s g} P}{R T}\right) \frac{1}{\rho_{s o o t}} \exp \left\{-\frac{T_{\gamma}}{T}\right\}
$$

\subsubsection{Oxidation model}

Akin to the derivation carried out for the surface growth rate, Eq. (7) can also be written as:

$$
\begin{aligned}
\omega_{\text {ox }, i} & =C_{O H} \eta_{\text {coll }}\left(\frac{X_{O H} P}{R T}\right) \sqrt{T}\left[\pi d_{i}^{2}\right]+C_{O_{2}}\left(\frac{X_{O_{2}} P}{R T}\right) \exp \left\{-\frac{T_{O_{2}}}{T}\right\} \sqrt{T}\left[\pi d_{i}^{2}\right] \\
& =\left.\frac{d m_{i}}{d t}\right|_{\text {remove mass by OH,i}}+\left.\frac{d m_{i}}{d t}\right|_{\text {remove mass by } O_{2}, i}
\end{aligned}
$$

This equation is used to calculate the rate of mass oxidized for individual soot particles by the oxidation agents $\mathrm{OH}$ and $\mathrm{O}_{2}$. The rate of change of diameter of the Lagrangian particle by oxidation via $\mathrm{OH}$ and $\mathrm{O}_{2}$ are similar in form as the surface growth as shown below:

$$
\begin{aligned}
& \left.\frac{d}{d t}\left(d_{i}\right)\right|_{\text {ox via } 0 H}=2 C_{O H} \eta_{\text {coll }}\left(\frac{X_{O H} P}{R T}\right) \frac{\sqrt{T}}{\rho_{\text {soot }}} \\
& \left.\frac{d}{d t}\left(d_{i}\right)\right|_{{\text {ox via } O_{2}}}=2 C_{O_{2}}\left(\frac{X_{O_{2}} P}{R T}\right) \frac{\sqrt{T}}{\rho_{\text {soot }}} \exp \left\{-\frac{T_{O_{2}}}{T}\right\}
\end{aligned}
$$

Once a Lagrangian soot particle is reduced to below a threshold diameter, it is assumed to be fully oxidized and is removed from the computational cell. The threshold value is set to 1.24 $\mathrm{nm}$ which is the same as the initial incipient soot particle size.

\subsection{Initialization of Lagrangian soot particles}

As mentioned earlier in Section 2.3.1.1, at least a single soot particle is present in the computational cell when the formation criterion for soot inception is met. The incipient soot number density in that cell can be computed using

$\frac{d N_{i n c}}{d t}=N_{A} \omega_{i n c}$

Modeling all the soot particles present in the computational cell as Lagrangian particles is computationally impractical due to the high soot number density in the order of magnitude of 


\section{ACCEPTED MANUSCRIPT}

$10^{17}$. Therefore, a special approach must be considered when initializing Lagrangian particles into the domain.

Two different Lagrangian particle initialization methods are introduced and elaborated as follows. In the first proposed method, a single Lagrangian particle is assumed to represent the population of soot inception particles formed at that instant in a computational cell. It is also assumed that all particles formed in that cell, at that instant, follows the same pathway (Katta et al., 2005) and size change as the Lagrangian particle. However, it is important to note that the initialization of Lagrangian particles is not dependent on the soot number present in the cell. Meanwhile, in the second proposed method, the soot number is considered when initializing the Lagrangian particles in the domain. Here, the number of Lagrangian particles available for formation, which is denoted as $N_{L}$, at each time step is kept constant. The distribution of these new particles into the computational cells that meet the formation criteria is based on the ratio of inception soot mass at each computational cell. The ratio of inception soot mass at cell $i, \theta_{i}$ is calculated using

$\theta_{i}=\frac{m_{\text {inc }, i}}{\sum m_{\text {inc }, i}}$

The ratio $\theta_{i}$ is the ratio of the inception soot mass at each individual cell to the total inception soot mass of the overall domain at that instance of time. At time step $t$, the number of Lagrangian particle initialized at a computational cell $i$ is calculated using $N_{p, i}=\theta_{i} N_{L}$

The proposed first and second methods are referred to as the Single Particle Method (SPM) and the Multiple Particle Method (MPM), respectively for brevity. Both methods assume that the initial velocity of the new particle formed follows the mean velocity of the cell it is formed in. When the Lagrangian particles are formed in a computational cell, the information of the total soot number present in the cell is stored together with the Lagrangian 


\section{ACCEPTED MANUSCRIPT}

particle. This information is henceforth referred as the initial soot population (ISP). This is an essential information to identify the soot number represented by the Lagrangian soot particle and will be used in the analysis of results in Section 2.4.1.

\subsubsection{Performance of SPM and MPM}

The performance of these two methods are tested in the Doshisha $n$-heptane case, following its operating conditions as previously reported in Section 2.1. For the MPM, two cases are tested with different $N_{L}, 500$ and 2000 , to investigate the effect of $N_{\mathrm{L}}$ on soot size distribution prediction. They are henceforth addressed as the MPM-500 and the MPM-2000, respectively. The probability density function (PDF) of the soot size computed by the SPM and MPM are compared in Fig. 4. Here, both the SPM and MPM have similar qualitative trends, but the MPM predicts a higher number of large soot particles than the SPM. To provide an explanation for the observation in Fig. 4, a series of PDF of the soot size is plotted based on the particle's ISP as shown in Fig. 5(a). All the Lagrangian particles are sorted into different bins with different ISP intervals, whereby each interval is 20000 particles. By categorizing all the Lagrangian particles into different ISP bins and plotting their corresponding PDF soot size, the effect of ISP on soot size prediction can be isolated from one another and analyzed independently. This method also allows a better platform to compare and analyze the results computed by the SPM and MPM.

At high ISP (above 80000 particles), the predicted size distributions by both the SPM and MPM are comparable. However, when ISP is below 80000 particles, the computed size distributions by the MPM start to shift towards larger soot size. The mean soot diameters at different ISP intervals for both methods are presented in Fig. 6. Similarly, the computed mean diameters by both methods coincide with each other at high ISP, but diverge when the ISP is lower than 80000 particles with the MPM predicting a larger mean diameter. These 


\section{ACCEPTED MANUSCRIPT}

differences in soot size distribution at different ISP intervals can be explained by analyzing the corresponding soot age distribution at different ISP intervals, as shown in Fig. 5(b).

The soot age of a particle is defined as the duration from its point of formation to the present instance. A low soot age indicates a young soot and vice versa. The SPM predicts a consistent trend in the age distribution for all ISP intervals whereby the number of particles decreases as the soot age increases. This implies that more young soot is present as compared to mature soot at different ISP intervals. The difference in the number of young and mature soot particles is expected as mature soot particles are mainly composed of remaining particles after undergoing surface growth and oxidation processes. At an ISP above 80000 particles, the MPM shows comparable age distribution trends to the ones predicted by the SPM. This explains the observed comparable size distributions between both methods in Fig. 5(a)(i-iii). However, the MPM age distribution starts to shift towards mature soot for ISP below 80000 particles as illustrated in Fig. 5(b)(iv-vii). This shift in soot age distribution implies that a high number of mature soot particles is present when the ISP is lower than 80000 particles. The presence of a high number of mature soot particles leads to the shift in soot size distribution when the ISP is below 80000 particles as shown in Fig. 5(a)(iv-vii). This reason also explains the difference in soot size distributions between the SPM and MPM in Fig. 4 whereby a higher number of large soot size is predicted by the MPM.

The effect of $N_{\mathrm{L}}$ on the size distribution is also investigated here by comparing the results of the MPM-500 and MPM-2000. No significant difference in the predicted PDF of soot size is detected when $N_{\mathrm{L}}$ changes as displayed in Fig. 4. This implies that increasing $N_{\mathrm{L}}$ has insignificant effect on the size distribution of the whole soot cloud. However, a distinct difference can be seen between the size distribution of the MPM-500 and MPM-2000 when they are compared separately at different ISP intervals, as presented in Fig. 5(a). At high ISP (above 80000 particles), the size distributions computed by both test cases correspond to 


\section{ACCEPTED MANUSCRIPT}

each other. However, at low ISP (below 80000 particles), the distributions predicted by the MPM-500 are biased towards the large soot size region. These phenomena at both high and low ISP are also evident in their predicted mean diameters as shown in Fig. 6. The reason for the bias towards large soot size when $N_{\mathrm{L}}$ is at 500 can be explained by its corresponding soot age distribution in Fig. 5(b). From a high ISP interval to a low ISP interval, the predicted soot age distribution starts to shift towards mature soot particles. It is important to highlight that no young soot $\left(A_{\mathrm{p}}=0.2 \mathrm{~ms}\right)$ is captured by the MPM-500 in Fig. 5(b)(v-vii). At the lowest ISP interval (0 - 20000 particles), only mature Lagrangian soot particles with soot ages within the interval of $0.6-0.8 \mathrm{~ms}$ are captured. This implies that information on particles formed at low ISP regions will be lost when a low $N_{\mathrm{L}}$ number is used. This would consequently cause the distribution to skew towards large soot size as more mature soot is present. A higher $N_{\mathrm{L}}$ is able to overcome this information loss, but will result in an increase in computational cost due to an increase in the number of particles present in the domain. In Fig. 5(b), young soot particles at all ISP intervals are captured when the $N_{\mathrm{L}}$ is set at 2000 . However, it is important to note that even at higher $N_{\mathrm{L}}$, the soot age distribution still does not correspond to the one predicted by the SPM. The profiles of the MPM-2000 still show increasing age distributions as opposed to the ones by the SPM. This increasing age distribution trend leads to the higher number of large soot size, and ultimately, causes the size distribution for the whole soot cloud to be skewed towards large soot size. This predicted age distribution by the MPM can be attributed to $\theta_{i}$ being dependent on the maximum inception soot mass which varies with time. A computational cell with an unchanged inception soot mass may have different numbers of Lagrangian particles formed at different time steps as the maximum inception soot mass varies with time step. This causes an inconsistency in the distribution of Lagrangian soot particles in the domain. 


\section{ACCEPTED MANUSCRIPT}

One way to solve this bias is by distributing the Lagrangian particles based on the ratio of inception mass to the maximum inception mass achieved in the full combustion process. This approach allows a more consistent distribution of Lagrangian particles in the domain over the whole combustion process. However, the maximum achievable inception mass for the whole combustion process must be known prior to the soot size study. This would cause a dependency on the accuracy of the computed maximum inception soot mass.

Another way to overcome the bias is to treat the population of soot particles formed at a computational cell as a parcel which stores the ISP. In addition to this, a soot number model has to be incorporated to take into account the loss of soot particles from the parcel as the soot parcel matures with time and migrates in the flame. The modeling for soot number is out of the scope of this paper and will be considered for future work.

From this investigation between the performance of the SPM and MPM, the SPM still emerges to be the relatively accurate approach for initializing Lagrangian particles based on the computed soot age distribution. Furthermore, it was previously shown that the size distributions by the SPM are comparable to the ones predicted by the MPM at high ISP intervals. This implies that the SPM is able to capture the distribution of high soot number despite not considering the soot number when initializing the Lagrangian particle.

\section{Validation of spray combustion models}

The first part of this section compares the simulation results of non-reacting fuel spray against the experimental measurements, in terms of the liquid and vapor penetration lengths as well as the mixture fraction. This is followed by the validation of the computed ID timings and LOL of reacting sprays using the experimental data. The non-reacting and reacting spray validation cases are carried out to ensure that the fuel-air distribution and the combustion characteristics are reasonably simulated, and uncertainties induced by these elements can be 


\section{ACCEPTED MANUSCRIPT}

minimized prior to studying the soot formation events. It is important to note that due to the lack of experimental data from the literature relating to non-reacting conditions for the Doshisha $n$-heptane case, the validations of non-reacting spray simulations are carried out for the Sandia $n$-dodecane test case only.

In the current simulation, the definition of liquid penetration length (LPL) is taken as the axial location from the injector to the location where $99 \%$ of the total liquid mass is found while the vapor penetration length (VPL) is taken as the maximum distance from the nozzle outlet to where the fuel mass fraction (or mixture fraction) is $0.1 \%$. As for the LOL, it is defined as the first axial location of Favre-averaged $\mathrm{OH}$ mass fraction which reaches $2 \%$ of its maximum value in the domain. The time averaging of the simulated LOL is carried out from 3.0 to $6.0 \mathrm{~ms}$ for the Sandia $n$-dodecane cases where injection duration is long $(>4 \mathrm{~ms})$. This corresponds to the experimental definition. For the Doshisha $n$-heptane case which has a short injection duration, the LOL is taken by averaging the simulated LOL from the start of ignition to the end of injection. The ID is defined as the time when the greatest rise of the average temperature is observed $(d T / d t)_{\max }$ and this definition remains consistent throughout the study. Although there are other definitions for the ID time, it has been reported that there is no significant discrepancy in the ID time between different ID definitions (Pang, Jangi, et al., 2015).

\subsection{Non-reacting spray simulations}

Comparisons between the computed and measured penetration lengths are provided in Fig. 8(a) for the Sandia $n$-dodecane test cases using the default and calibrated model constants. In general, the tuned model shows an improved VPL prediction as compared to the measurement. The computed and measured mean radial mixture fraction profiles are compared in Fig. 8(b). The overall trend of the mixture fraction profiles agrees with the 


\section{ACCEPTED MANUSCRIPT}

experimental data although the mean mixture fraction profiles at both $x=25 \mathrm{~mm}$ and $45 \mathrm{~mm}$ from the injector are slightly underestimated as compared to the experimental results. These results imply that the air-fuel distributions are reasonably predicted by the model. It is important to note that the model constants used in the non-reacting validation cases remained unchanged in the numerical studies of the reacting flow.

\subsection{Reacting spray simulations}

Fig. 9 shows the comparison between the predicted heat release rate (HRR) using the current model to the experimental and simulation results presented by Ito et al. (2004) for the Doshisha $n$-heptane case. The current simulated peak HRR is overestimated. This may be due to the use of the WSR model. The peak value may be reduced by incorporating advanced turbulent combustion models such as the TPDF (Bhattacharjee \& Haworth, 2013). Despite this, the time taken for the HRR to reach its peak value coincides with that of the experimental measurement. It is recorded at approximately $0.7 \mathrm{~ms}$ after the start of injection (ASOI). The time of peak HRR of the combustion phase is particularly significant for soot prediction since it is an indication of soot onset as experimentally observed by Singh et al. (2005).

Fig. 10 shows the comparison of the experimental and predicted ID and LOL for both the Doshisha $n$-heptane and the Sandia $n$-dodecane test cases. As seen, the simulated LOL for the Doshisha test case is $16.2 \mathrm{~mm}$ which is shorter than the experimental LOL of $40 \mathrm{~mm}$. Spray combustion characteristics are dependent on accurate prediction of the spray phenomenon. Therefore, the underprediction in LOL is possibly due to the discrepancies in the predicted non-reacting spray characteristics such as LPL, VPL and/or mixture fraction. The absence of non-reacting data makes it difficult to verify if the spray characteristics predicted are comparable to the measurements. Another reason for the disagreement between 


\section{ACCEPTED MANUSCRIPT}

the simulated and measured LOL may be due to the difference in LOL definition used in both studies as the experimental LOL definition for the Doshisha case is not explicitly reported. It is uncertain whether the measured LOL was obtained from a certain time-step ASOI or timeaveraged. Despite this, the ID is accurately predicted by the simulation to be $0.62 \mathrm{~ms}$ while experimental ID is approximately $0.7 \mathrm{~ms}$. Furthermore, it is shown later that the predicted soot distribution and position correspond reasonably well with the experimental observation.

As for the Sandia $n$-dodecane case, the computed LOLs are overpredicted for both $\mathrm{O}_{2}$ concentration cases. The computed LOLs for the $15 \%$ and $21 \% \mathrm{O}_{2}$ concentration cases have relative differences of $11 \%$ and of $32 \%$, respectively with the experimental data. The reason for this overestimation can be attributed to the use of the WSR model. Pei et al. (2015) have demonstrated that better agreement between the predicted and measured LOLs under different ambient oxygen concentrations can be achieved by incorporating TPDF. Similar to LOL, the simulated IDs are systematically overpredicted for both $\mathrm{O}_{2}$ concentration levels. Similar overestimations of ID were also reported in (D'Errico et al., 2014; Luo et al., 2014; Pandurangi et al., 2016; Pang, Poon, Ng, Gan, \& Schramm, 2015) when the same chemical mechanism was used. The IDs were shown by Pei et al. (2015) and D'Errico et al. (2014) to be insensitive to the type of TCI model used. The analysis carried out by Pei et al. (2015) suggested that the discrepancy in ID was mainly attributed to the modeling of the chemical kinetics. This was evident in the LES numerical study by Wehrfritz et al. (2016) who demonstrated good prediction for ID across varying oxygen concentrations using a different n-dodecane mechanism with 130-species and 2395-reactions (Ranzi et al., 2014).

It is important to note that this discrepancy in LOL can lead to a discrepancy in the soot formation process. A longer LOL would imply that more air entrainment occurs which consequently result in a lower equivalence ratio at the LOL location. With lower equivalence ratio, a lower amount of soot is formed in general. Furthermore, a longer LOL would lead to 


\section{ACCEPTED MANUSCRIPT}

the quasi-steady soot distribution to be further downstream than the measured distribution. Despite predicting the soot distribution to be further downstream, both the Eulerian and Lagrangian soot models are still able to capture the variation of soot spatial distribution with respect to the change in ambient $\mathrm{O}_{2}$ level. These phenomena are later seen in Section 4.2.

\section{Evaluation of soot tracking model}

The performance of the proposed LST model in predicting the temporal soot cloud evolution and the primary soot particle size distribution is assessed in this section. Sensitivity studies on the mesh resolution and soot sub-models are also discussed.

\subsection{Doshisha n-heptane test case}

\subsubsection{Mesh independence study}

A convergence study is first carried out to ensure that the predicted primary soot size distribution results have achieved grid independence. Three different meshes, $0.50 \mathrm{~mm} \mathrm{x}$ $0.50 \mathrm{~mm}$ (coarse), $0.25 \mathrm{~mm} \times 0.50 \mathrm{~mm}$ (intermediate) and $0.25 \mathrm{~mm} \times 0.25 \mathrm{~mm}$ (fine) are tested. It should be noted that non-reacting and reacting test cases are carried out for all three meshes. Similar to the previous exercise, the non-reacting test case involves comparing the LPL, VPL and radial mixture fraction, whereas the reacting test case involves comparing ID and LOL for all three meshes. Fig. 11 shows the non-reacting results by all three meshes. The computed ID and LOL for the meshes are tabulated in Table 3. The simulated LOL is obtained by averaging the simulated LOL from the start of ignition to the end of injection. The predicted LPL, VPL and radial mixture fraction are shown in Fig. 11 to be insensitive to the mesh change. Similarly, the computed ID and LOL show little difference when reducing mesh size. The dependency of the primary soot size distribution results on mesh resolution are next evaluated. 
ACCEPTED MANUSCRIPT

Table 3: Ignition delay and lift-off length for different mesh configurations.

\begin{tabular}{llll}
\hline Mesh & $0.50 \mathrm{~mm} \times 0.50 \mathrm{~mm}$ & $0.25 \mathrm{~mm} \times 0.50 \mathrm{~mm}$ & $0.25 \mathrm{~mm} \times 0.25 \mathrm{~mm}$ \\
\hline Ignition Delay [ms] & 0.62 & 0.575 & 0.573 \\
Lift-off Length [mm] & 16.2 & 16.3 & 16.6 \\
\hline
\end{tabular}

Fig. 12 shows the predicted primary soot size distribution in the whole soot cloud at $t=1.5 \mathrm{~ms}$ ASOI using various mesh configurations. The PDF for the primary soot size in Fig. 12 is plotted by taking the number of Lagrangian particles which are within a size range and dividing it by the total number of Lagrangian soot particles. When the $0.25 \mathrm{~mm} \times 0.25 \mathrm{~mm}$ and a $0.25 \mathrm{~mm} \times 0.50 \mathrm{~mm}$ computational grids are used, it implies that for the same area, the number of Lagrangian particles created during the soot inception process is four and two times more than that of the $0.50 \mathrm{~mm} \times 0.50 \mathrm{~mm}$ grid. Similarly, it is shown that the results generated by the mesh with the size of $0.50 \mathrm{~mm}$ radially and axially reaches mesh independence as there is no significant difference in the size distribution when further refinement is carried out on the mesh. It is also worth noting that the particle size distributions demonstrate a lognormal shape, which agrees with the soot particle size distributions recorded from both flame and diesel engine experiments (Aizawa et al., 2015; Kook, Zhang, Szeto, Pickett, \& Aizawa, 2013; Kuribayashi, Ishizuka, \& Aizawa, 2013; Yamaguchi, Kondo, Nishigai, Takano, \& Aizawa, 2011). The numerical soot studies performed in the remaining part of the paper are carried out using the $0.50 \mathrm{~mm} \times 0.50 \mathrm{~mm}$ grid.

\subsubsection{Mean soot diameter distribution}

The performance of the LST models for the Doshisha $n$-heptane case are evaluated with respect to the MOM simulation results and time-resolved Laser Induced Incandescence (LII) measurement reported by Ito et al. (2004). Besides comparing against the simulation and 


\section{ACCEPTED MANUSCRIPT}

experimental results obtained by Ito et al. (2004), the predictive capability of the LST model is also compared against its Eulerian counterpart, the MB soot model. These comparisons of the simulated and experimental mean soot diameters can be found in Fig. 13. The Eulerian MB mean soot diameter is computed using Eq. (1) while the LST mean soot diameter, $\bar{d}_{p}$ in a computational cell $j$ is calculated using the expression below:

$\bar{d}_{p, j}=\left[\frac{\sum_{i=1}^{N_{p, j}}\left(d_{p, i}{ }^{3}\right)}{N_{p, j}}\right]^{1 / 3}$

where $N_{p, j}$ denotes the total number of Lagrangian particles in cell $j$. The mean soot diameters observed in the experiment and those computed using the MOM by Ito et al. (2004) are initially small throughout the soot cloud at $1 \mathrm{~ms}$. The soot particles then slowly increase in size, starting from the periphery of the jet as the soot cloud moves downstream. These features are replicated using the LST model. On the contrary, the Eulerian method fails to capture this evolution. At $1.0 \mathrm{~ms}$, the Eulerian result is still comparable to the MOM and LST results. However, at later times, the Eulerian model predicts the peak soot size to be at the head of the spray jet rather than at the periphery of the flame. This implies that the averaged soot size calculated based on the mono-disperse assumption in the Eulerian method is a less appropriate representation of the soot sizing distribution. As for its Lagrangian counterpart, the poly-disperse assumption is considered where all the Lagrangian particles evolve independently based on their individual sizes and positions in the combustion domain.

As mentioned in Section 3.2, the LOL is underpredicted as compared to the measured data. Therefore, the soot results obtained here are interpreted with care. A shorter simulated LOL suggests a lower air entrainment and air-fuel mixture as compared to the experiment. Therefore, the quantitative soot prediction by the LST may not correspond to the measured data and the ones predicted by the MOM. Despite underpredicting LOL, the mean diameter 


\section{ACCEPTED MANUSCRIPT}

distribution predicted by the LST agrees with the MOM results and measurements while the Eulerian method fails in this respect.

\subsection{Sandia n-dodecane test cases}

\subsubsection{Transient soot cloud distribution}

The LST model is subsequently applied to simulate the soot formation in the Sandia $n$ dodecane cases. Fig. 14 and 15 compare the simulated and experimental soot cloud evolutions before reaching quasi-steady state for the Sandia $n$-dodecane spray case at both ambient $\mathrm{O}_{2}$ levels of $15 \%$ and $21 \%$, respectively. The simulated soot cloud using the LST and Eulerian methods are represented by the primary soot size distribution and the soot mass fraction, respectively. In contrast, the $K L$ factor measured in the experiment is used to represent the experimental soot cloud development. $K$ is the absorption coefficient while $L$ is a measure of the path length along which the measurement is made. The $K L$ factor is an indication of the optical thickness derived from laser-extinction soot measurements (Pickett $\&$ Siebers, 2004). The $K L$ factor is proportional to the mass of soot along the line of sight of the extinction measurement (Pickett \& Siebers, 2004) so it can be compared to the predicted primary soot size distribution along the same axial region. This is because the region with high soot mass would correspond to the region with large soot size and high number of particles. These experimental images are snapshots extracted from the video provided by the Engine Combustion Network (ECN, 2010). Apart from that, the spatial distribution of primary soot diameter is used to denote the simulated soot cloud evolutions.

As shown in Fig. 14, the temporal soot cloud evolution predicted by the LST for the $15 \% \mathrm{O}_{2}$ case coincides well with the experimental soot cloud. At $0.8 \mathrm{~ms}$ ASOI, soot particles start to form at the location $35 \mathrm{~mm}$ away from the injector although only a weak signal is recorded in the experiment. The LST model predicts the soot particles to be present at a 


\section{ACCEPTED MANUSCRIPT}

similar location and injection timing. The soot cloud starts to grow widely as the combustion progresses. The development of the soot cloud is reproduced by the LST model. The Eulerian predictions coincide with the LST results as well as the measured distribution spatially. However, the predicted soot onset is delayed by $0.4 \mathrm{~ms}$. The temporal soot cloud evolution in the $21 \%$ case is similarly compared between the LST, Eulerian and experimental data in Fig. 15. At approximately $0.4 \mathrm{~ms}$ ASOI, a noticeable soot cloud is observed in the experiment at the location $25 \mathrm{~mm}$ away from the injector. The predicted soot onset via the LST occurs at a similar location, but the onset timing is delayed till $0.5 \mathrm{~ms}$ ASOI. For the Eulerian prediction, the predicted soot onset timing is, again, delayed to $1.2 \mathrm{~ms}$ ASOI. Despite having a delayed soot onset, the predicted soot head coincides with the measured spray head and the predicted soot distribution by the LST. The prediction of soot onset timing and location by the LST at $15 \%$ and $21 \%$ oxygen concentration coincide with the simulated soot onset timing and location obtained by Pandurangi et al. (2016) who used Leung's two-equation soot model (Leung et al., 1991) to compare the Eulerian soot results against the experimental soot results.

\subsubsection{Quasi-steady soot cloud distribution}

The quasi-steady soot cloud distribution computed using the LST is displayed in Fig. 16. Akin to Section 4.2.1, the simulated soot clouds using the LST and Eulerian methods are represented by the primary soot size distribution and the soot mass fraction, respectively. Conversely, the experimentally determined $K L$ factor is used to represent the soot cloud development. As illustrated in Fig. 16, the experimental data (Cenker, Bruneaux, Pickett, \& Schulz, 2013) denote that the peak soot location for the $21 \% \mathrm{O}_{2}$ case is approximately $20 \mathrm{~mm}$ further upstream relative to that of the $15 \%$ case. Similarly, the soot cloud predictions using the LST and Eulerian methods demonstrate this shift when the ambient $\mathrm{O}_{2}$ level increases. For the $15 \%$ case, the distribution of maximum primary soot size spans from $75 \mathrm{~mm}$ to 


\section{ACCEPTED MANUSCRIPT}

$100 \mathrm{~mm}$ from the injector along the spray axis as shown in Fig. 16(a). Meanwhile, the

Eulerian soot distribution spans from $65 \mathrm{~mm}$ to $95 \mathrm{~mm}$ from the injector location, with the peak soot location at $80 \mathrm{~mm}$ from the injector. For the higher $\mathrm{O}_{2}$ content of $21 \%$, the distribution of maximum primary soot size spans from $60 \mathrm{~mm}$ to $90 \mathrm{~mm}$ from the injector location along the spray axis, as presented in Fig. 16(b). The Eulerian method predicts a maximum peak soot location $65 \mathrm{~mm}$ and with a total soot cloud span from $40 \mathrm{~mm}$ to $85 \mathrm{~mm}$. The predicted Eulerian soot spans correspond well with the maximum primary soot size spans predicted by the LST at both $\mathrm{O}_{2}$ levels albeit both simulated soot distributions being further downstream than the measured distribution. This can be attributed to the overprediction of LOL as discussed in Section 3.2. Scaling the gas-phase profile was found to be an effective method to resolve the spatial discrepancy in soot distribution (Yapp et al., 2016). However, addressing the discrepancy in peak soot location is beyond the scope of the present work.

In Fig. 17, the integrated soot masses obtained in a thin $(1 \mathrm{~mm})$ radial cross-section inside the jet are presented as a function of axial distance. The method to obtain the integrated soot mass experimentally was reported by Cenker et al. (2013). The integrated soot mass for the LST model is obtained by summing all the Lagrangian particles within $\pm 0.5 \mathrm{~mm}$ of the vicinity of the desired axial location. The measured soot mass is shown to increase when $\mathrm{O}_{2}$ content decreases. This is similarly captured by the simulated soot masses, but are 3 times higher in magnitude than the measured data. The reason for this overprediction can be attributed to the Moss-Brookes soot model assuming a linear dependency for the soot surface area in the surface growth model. The work by Pang et al. (2015) showed that a linear dependency for soot surface area can lead to a higher computed peak SVF by a factor of 4 relative to the results obtained by the square root dependency. As SVF is directly linked to soot mass, the higher SVF also implies a higher predicted soot mass. As the LST model is 


\section{ACCEPTED MANUSCRIPT}

based on the Moss-Brookes soot model, it is possible that the results obtained is influenced by this linear dependency assumption.

The effect of ambient $\mathrm{O}_{2}$ levels on the location of large primary soot predicted by the LST model coincides with the measurements by Kuribayashi et al. (2014), who studied the effect of $\mathrm{O}_{2}$ level on primary soot size in diesel spray flame. The maximum soot size predicted in both the $15 \%$ and $21 \%$ cases are similar to one another which also agrees with the experimental data presented by Kuribayashi et al. (2014). However, another experimental study by Cenker et al. (2014) showed contradictory results, whereby the maximum soot size for the $21 \%$ case was higher than the $15 \%$ case. This contradiction in the experimental data could be due to experimental uncertainties, and further experimental studies should be carried out to verify the $\mathrm{O}_{2}$ level effect on primary soot size. Nonetheless, the predicted maximum primary soot size for both $\mathrm{O}_{2}$ levels fall within the same order of magnitude as the primary soot size measured by both experimental studies.

\subsubsection{Primary soot particle size distribution}

An ex-situ soot study was reported by Cenker et al. (2014) for the $n$-dodecane fuel in the same Sandia combustion vessel configuration (ECN, 2010) as mentioned in Section 2.1. During the $n$-dodecane spray flame combustion, soot particles were sampled thermophoretically at different axial locations along the soot cloud. The deposited soot samples were then analyzed to obtain the diameter of the primary soot particles. The details of the experimental setup can be found in (Cenker et al., 2014) while the high-resolution transmission electron microscopy (HR-TEM) measurement techniques and the primary particle definition are discussed in (Kuribayashi et al., 2013). The experimental primary soot size distribution of the $21 \% \mathrm{O}_{2}$ Sandia $n$-dodecane case (Cenker et al., 2014) as shown in Fig. 18 is adopted to evaluate the performance of the proposed LST model as the data set for this 


\section{ACCEPTED MANUSCRIPT}

case provides three different locations across the soot cloud which is useful to evaluate the model.

Based on the quasi-steady state soot distribution in Section 4.2.2, it is apparent that the current model simulates the leading 'head vortex' to be further downstream than the measured distribution. Hence, it is not surprising that the experimental and simulated size distributions do not match at the same axial location. Instead of shifting the locations arbitrarily for comparison purposes, all the Lagrangian particles along the spray axis are recorded and the analysis is carried out from the start of ignition to $6.0 \mathrm{~ms}$ ASOI. The sampling region is set to be $\pm 2.5 \mathrm{~mm}$ axially and radially (as shown in Fig. 2), starting from $30 \mathrm{~mm}$ to $100 \mathrm{~mm}$, with an interval of $5 \mathrm{~mm}$. This covers the soot particles near the spray axis and hence is similar to the experimental practice. Fig. 19 shows the primary soot size distribution at selected locations along the spray axis for the Sandia $21 \% \mathrm{O}_{2} n$-dodecane spray case. The PDF for the primary soot size is plotted following the same method described in Section 4.1.1. The maximum primary soot size is shown to increase from $x=30 \mathrm{~mm}$ to $100 \mathrm{~mm}$ from the injector location. The peak primary soot size of $46 \mathrm{~nm}$ is obtained at $x=80 \mathrm{~mm}$ from the location of the injector, which coincides with the span of the maximum primary soot size distribution presented previously in Fig. 16(b). The increasing maximum primary soot size from $x=30 \mathrm{~mm}$ to $80 \mathrm{~mm}$ from the location of the injector also indicates that the soot formation process becomes more dominant. Further downstream along the spray axis, i.e. $x=80 \mathrm{~mm}$ to $100 \mathrm{~mm}$ from the location of the injector, the maximum primary soot size is shown to decrease from $46 \mathrm{~nm}$ to $26 \mathrm{~nm}$ (approximately $44 \%$ reduction). The reduction rate of the maximum primary soot size coincides with the measured reduction rate from $x=36 \mathrm{~mm}$ to $60 \mathrm{~mm}$, which is $47.6 \%$. This observation of decreasing maximum primary soot size shows that soot oxidation process in this region is the dominant process over surface growth process. These findings indicate that the LST model can capture the variation in 


\section{ACCEPTED MANUSCRIPT}

primary soot particle size across the soot cloud. Also, the associated maximum primary soot particle sizes predicted fall into the same order of magnitude as those measured in the experiment. The largest predicted primary soot size is approximately $10 \%$ larger than the measured peak size. Furthermore, the model is able to capture the lognormal shape of the primary soot size distribution which is one of the characteristics of the measured primary size distribution shown in Fig. 18. The effects of different sub-models on primary soot size distribution are next investigated in the following sections.

\subsubsection{Sensitivity studies}

A test matrix as shown in Table 4 is constructed to investigate the effects of soot surface ageing as well as soot oxidation due to $\mathrm{O}_{2}$ and $\mathrm{OH}$ on the LST model predictions. The sensitivity of the $\mathrm{O}_{2}$ oxidation model constant, $C_{O_{2}}$, is tested by increasing it by a factor 2 while the $\mathrm{OH}$ collision coefficient, $\eta_{\text {coll }}$, is increased from the default value of 0.04 (Brookes \& Moss, 1999) to 0.13 (Leung et al., 1991). The sensitivities of the surface ageing and soot oxidation rates are examined using the $21 \% \mathrm{O}_{2}$ Sandia $n$-dodecane test case. It is worth mentioning that the transient and quasi-steady soot cloud distributions remain unchanged when the tested model parameters are varied. However, as will be discussed later, the primary soot particle size distributions are shown to vary with the model parameters.

Table 4: Test matrix to study the effect of increasing oxidation factor and including surface ageing.

\begin{tabular}{cll}
\hline Configuration & Test case name & Descriptions \\
\hline 1 & Ageing (baseline) & Consider surface ageing only \\
2 & No Ageing & No surface ageing considered \\
3 & Ageing $+\mathrm{O}_{2}$ & Consider surface ageing \& $\mathrm{O}_{2}$ model constant $\times 2$ \\
4 & Ageing $+\mathrm{OH}$ & Consider surface ageing \& $\mathrm{OH}$ collision coefficient $=0.13$ \\
\hline
\end{tabular}




\section{ACCEPTED MANUSCRIPT}

The effect of surface ageing on the primary soot size distribution at various axial

locations can be seen in Fig. 19. The variation in the primary soot size across the soot formation and oxidation zones predicted using configuration 2 are similar to that captured by configuration 1 . The dominant region of soot formation spans from $x=30 \mathrm{~mm}$ to $80 \mathrm{~mm}$ from the location of the injector while the oxidation dominant region is downstream of $x=80 \mathrm{~mm}$. The peak primary soot size is also obtained at $x=80 \mathrm{~mm}$ from the location of the injector. Despite these similarities between configuration 1 and 2, the maximum primary soot sizes predicted by configuration 2 along the various axial locations are larger. The peak primary soot size predicted by configuration 2 reaches 110nm, which is approximately 3 times higher than the one predicted in configuration 1. Furthermore, the lognormal shape is not consistently captured in configuration 2 , for instance at $x=80 \mathrm{~mm}$ and $x=90 \mathrm{~mm}$ from the location of the injector. These findings imply that surface ageing plays a significant role in modeling the primary soot size distribution.

Next, the effects of increasing the rates of $\mathrm{O}_{2}$ and $\mathrm{OH}$ oxidation on the primary soot size distribution are investigated. The results from configuration 3 and 4 are plotted together with the baseline case (configuration 1) in Fig. 20. There is not much difference in the predicted primary soot size distributions in the soot formation region $(x=30 \mathrm{~mm}$ to $80 \mathrm{~mm}$ from injector location) by configurations 3 and 4 . Furthermore, in this formation region, they are also comparable to the results obtained from the baseline case. Hence, only the results within the soot oxidation region, i.e. at $x=75 \mathrm{~mm}$ to $100 \mathrm{~mm}$ from the injector location with an interval of $5 \mathrm{~mm}$ are presented. For configuration 3, a significant amount of primary soot particles is still present at $x=100 \mathrm{~mm}$ from the injector location, with a maximum size of $24 \mathrm{~nm}$. This trend is also observed in the baseline case, but with a higher number of large soot particles. However, for configuration 4 where $\mathrm{OH}$ rates is increased, the primary soot particles are shown to be fully oxidized before reaching $x=100 \mathrm{~nm}$. This finding coincides 


\section{ACCEPTED MANUSCRIPT}

with the $\mathrm{OH}$ distribution depicted in Fig. 21, which shows a high concentration of $\mathrm{OH}$ species in the region between $x=95 \mathrm{~mm}$ to $x=105 \mathrm{~mm}$ from the injector location along the spray axis. With a higher $\mathrm{OH}$ oxidation rate in configuration 4 , soot particles are oxidized faster in the region where $\mathrm{OH}$ species concentration is high.

\section{Concluding remarks}

A Lagrangian soot tracking (LST) model is developed and applied to simulate the primary soot particles in $n$-heptane and $n$-dodecane spray combustion. The Moss-Brookes soot model is used in the current study and is modified to fit into the Lagrangian framework. The LST model performance is first evaluated using the results from the Eulerian counterpart as well as the numerical and experimental data from the literature. Comparisons with the MOM results and the experimental data in the Doshisha $n$-heptane test case show that the newly developed LST model reproduces the mean diameter distribution while its Eulerian counterpart fails to capture this soot characteristic.

In the Sandia $n$-dodecane test case, the temporal distribution of primary soot particles predicted by the LST model is qualitatively comparable to the experimental soot evolution. At quasi-steady state, the variation in the location of region with large primary soot particles with respect to the change in ambient $\mathrm{O}_{2}$ levels is captured, although the simulated one is observed to be further downstream as compared to the measured soot volume fraction. The current simulation results also show that the LST model can capture the variation of the primary soot particle size across the soot formation and oxidation zones, in which the associated maximum primary soot particle sizes predicted fall in the same order of magnitude as those measured in the experiment. Furthermore, the model is able to capture the lognormal shape of the primary soot size distribution which is one of the characteristics of the measured primary size distribution. 


\section{ACCEPTED MANUSCRIPT}

The current work also investigates the effects of surface ageing and oxidation rates on the predictions of primary soot size distributions along the spray axis. It is found that with the absence of the surface ageing, the maximum primary soot particle diameter size increases by at least a factor of 2. In addition to this, the lognormal shape is not observed in the soot oxidation zones when surface ageing is not taken into account. An increase in $\mathrm{O}_{2}$ oxidation rate has insignificant effect on the primary soot size distribution. In contrast, a higher $\mathrm{OH}$ oxidation rate causes the primary soot particles to be fully oxidized at a more upstream location. The transient primary soot evolution and quasi-steady soot distribution are, however, independent from these variations.

In general, the LST model with surface ageing factor is demonstrated to be able to more accurately predict the primary soot size distribution. Transient soot evolutions are also reasonably well predicted. The proposed LST model would serve as a good tool for industrial-level design of diesel engines in which the primary soot size distribution is important. The model can be implemented to study both soot path and its size evolution in diesel engines such as that presented by Mahmood, LaRocca, Shayler, Bonatesta, \& Pegg (2012). In addition to knowing the soot size and migration path, the trajectories of each Lagrangian particles can be used to study the various factors affecting the primary soot size in diesel engines.

\section{Acknowledgment}

This research is conducted under the financial support provided by the University of Nottingham Malaysia Campus through the Dean's Scholarship Award.

\section{References}

Adkins, E. M., \& Miller, J. H. (2015). Extinction measurements for optical band gap determination of soot in a series of nitrogen-diluted ethylene/air non-premixed flames. Physical Chemistry Chemical Physics, 17(4), 2686-2695. 
http://doi.org/10.1039/C4CP04452E

Aizawa, T., Takahata, N., Okabe, K., \& Mizutani, Y. (2015). Effect of Fuel Aromatics on InFlame Diesel Soot Nanostructure via HRTEM. SAE Technical Paper.

Akridis, P., \& Rigopoulos, S. (2016). Modelling of soot formation in laminar diffusion flames using a comprehensive CFD-PBE model with detailed gas-phase chemistry. Combustion Theory and Modelling, 1-14. http://doi.org/10.1080/13647830.2016.1213426

ANSYS FLUENT 14.5 User's Guide. (2012). Fluent Inc., Lebanon, NH.

Balthasar, M., \& Kraft, M. (2003). A stochastic approach to calculate the particle size distribution function of soot particles in laminar premixed flames. Combustion and Flame, 133(3), 289-298.

Bhattacharjee, S., \& Haworth, D. C. (2013). Simulations of transient n-heptane and ndodecane spray flames under engine-relevant conditions using a transported PDF method. Combustion and Flame, 160(10), 2083-2102. http://doi.org/http://dx.doi.org/10.1016/j.combustflame.2013.05.003

Bockhorn, H. (2009). Combustion Generated Fine Carbonaceous Particles: Proceedings of an International Workshop Held in Villa Orlandi, Anacapri, May 13-16, 2007. KIT Scientific Publishing.

Bolla, M., Wright, Y. M., Boulouchos, K., Borghesi, G., \& Mastorakos, E. (2013). Soot formation modeling of $\mathrm{n}$-heptane sprays under diesel engine conditions using the conditional moment closure approach. Combustion Science and Technology, 185(5), 766-793.

Botero, M. L., Adkins, E. M., González-Calera, S., Miller, H., \& Kraft, M. (2016). PAH structure analysis of soot in a non-premixed flame using high-resolution transmission electron microscopy and optical band gap analysis. Combustion and Flame, 164, 250258. http://doi.org/http://dx.doi.org/10.1016/j.combustflame.2015.11.022

Brookes, S. J., \& Moss, J. B. (1999). Predictions of soot and thermal radiation properties in confined turbulent jet diffusion flames. Combustion and Flame, 116(4), 486-503.

Cenker, E., Bruneaux, G., Pickett, L., \& Schulz, C. (2013). Study of soot formation and oxidation in the engine combustion network (ecn), spray a: Effects of ambient temperature and oxygen concentration. SAE International Journal of Engines, 6(2013- 
01-0901), 352-365.

Cenker, E., Gilles, B., \& Christof, S. (2014). Imaging measurements of soot particle size and soot volume fraction with laser-induced incandescence at Diesel engine conditions. Ph.D. diss., Ecole Centrale Paris. Retrieved from https://tel.archives-ouvertes.fr/tel01127391

Cheng, X., Ng, H. K., Gan, S., Ho, J. H., \& Pang, K. M. (2015). Development and validation of a generic reduced chemical kinetic mechanism for CFD spray combustion modelling of biodiesel fuels. Combustion and Flame, 162(6), 2354-2370.

D’Alessio, A., Barone, A. C., Cau, R., D’Anna, A., \& Minutolo, P. (2005). Surface deposition and coagulation efficiency of combustion generated nanoparticles in the size range from 1 to 10nm. Proceedings of the Combustion Institute, 30(2), 2595-2603.

D’Errico, G., Lucchini, T., Contino, F., Jangi, M., \& Bai, X.-S. (2014). Comparison of wellmixed and multiple representative interactive flamelet approaches for diesel spray combustion modelling. Combustion Theory and Modelling, 18(1), 65-88.

Dobbins, R. A., Fletcher, R. A., \& Lu, W. (1995). Laser microprobe analysis of soot precursor particles and carbonaceous soot. Combustion and Flame, 100(1), 301-309.

Dukowicz, J. K. (1980). A particle-fluid numerical model for liquid sprays. Journal of Computational Physics, 35(2), 229-253.

ECN. (2010). Engine Combustion Network. Retrieved from www.sandia.gov/ecn/

Fairweather, M., Jones, W. P., \& Lindstedt, R. P. (1992). Predictions of radiative transfer from a turbulent reacting jet in a cross-wind. Combustion and Flame, 89(1), 45-63.

Franken, T., \& Mauss, F. (2016). Development of Methodology for Predictive Diesel Combustion Simulation Using OD Stochastic Reactor Model. SAE Technical Paper.

Frenklach, M. (2002a). Method of moments with interpolative closure. Chemical Engineering Science, 57(12), 2229-2239.

Frenklach, M. (2002b). Reaction mechanism of soot formation in flames. Physical Chemistry Chemical Physics, 4(11), 2028-2037.

Frenklach, M., \& Wang, H. (1991). Detailed modeling of soot particle nucleation and growth. Symposium (International) on Combustion, 23(1), 1559-1566.

Frossling, N. (1956). Evaporation, heat transfer, and velocity distribution in two-dimensional 


\section{ACCEPTED MANUSCRIPT}

and rotationally symmetrical laminar boundary-layer flow. DTIC Document.

Fuentes, A., Rouvreau, S., Joulain, P., Vantelon, J.-P., Legros, G., Torero, J. L., \& Fernandez-Pello, A. C. (2007). Sooting behavior dynamics of a non-buoyant laminar diffusion flame. Combustion Science and Technology, 179(1-2), 3-19.

Gelbard, F., \& Seinfeld, J. H. (1980). Simulation of multicomponent aerosol dynamics. Journal of Colloid and Interface Science, 78(2), 485-501.

Gelbard, F., Tambour, Y., \& Seinfeld, J. H. (1980). Sectional representations for simulating aerosol dynamics. Journal of Colloid and Interface Science, 76(2), 541-556.

Hadavi, S. A., Li, H., Biller, P., Lea-Langton, A., Andrews, G., \& Przybyla, G. (2012). Rape seed oil B100 diesel engine particulate emissions: The influence of intake oxygen on particle size distribution. SAE Technical Paper.

Harris, S. J., \& Weiner, A. M. (1985). Chemical kinetics of soot particle growth. Annual Review of Physical Chemistry, 36(1), 31-52.

Haynes, B. S., \& Wagner, H. G. (1981). Soot formation. Progress in Energy and Combustion Science, 7(4), 229-273.

Haynes, B. S., \& Wagner, H. G. (1982). The surface growth phenomenon in soot formation. Zeitschrift Für Physikalische Chemie, 133(2), 201-213.

Herdman, J. D., Connelly, B. C., Smooke, M. D., Long, M. B., \& Miller, J. H. (2011). A comparison of Raman signatures and laser-induced incandescence with direct numerical simulation of soot growth in non-premixed ethylene/air flames. Carbon, 49(15), 52985311. http://doi.org/http://dx.doi.org/10.1016/j.carbon.2011.07.050

Hiroyasu, H., Kadota, T., \& Arai, M. (1983). Development and use of a spray combustion modeling to predict diesel engine efficiency and pollutant emissions: Part 1 combustion modeling. Bulletin of JSME, 26(214), 569-575.

Issa, R. I. (1986). Solution of the implicitly discretised fluid flow equations by operatorsplitting. Journal of Computational Physics, 62(1), 40-65.

Ito, T., Hosaka, T., Ueda, M., Senda, J., \& Fujimoto, H. (2004). Detailed kinetic modeling and laser diagnostics of soot formation process in diesel jet flame. SAE Technical Paper.

Jangi, M., D’Errico, G., Bai, X.-S., \& Lucchini, T. (2012). Numerical simulation of the ECN 


\section{ACCEPTED MANUSCRIPT}

Spray A using multidimensional chemistry coordinate mapping: $n$-Dodecane diesel combustion. SAE Technical Paper.

Janicka, J., \& Peters, N. (1982). Prediction of turbulent jet diffusion flame lift-off using a PDF transport equation. In Symposium (International) on Combustion (Vol. 19, pp. 367374). Elsevier.

Kaminaga, T., Kusaka, J., \& Ishii, Y. (2008). A three-dimensional numerical study on exhaust gas emissions from a medium-duty diesel engine using a phenomenological soot particle formation model combined with detailed chemistry. International Journal of Engine Research, 9(4), 283-296.

Karlsson, A., Magnusson, I., Balthasar, M., \& Mauss, F. (1998). Simulation of soot formation under diesel engine conditions using a detailed kinetic soot model. SAE Technical Paper.

Katta, V. R., Blevins, L. G., \& Roquemore, W. M. (2005). Dynamics of an inverse diffusion flame and its role in polycyclic-aromatic-hydrocarbon and soot formation. Combustion and Flame, 142(1), 33-51.

Katta, V. R., Forlines, R. A., Roquemore, W. M., Anderson, W. S., Zelina, J., Gord, J. R., ... Roy, S. (2011). Experimental and computational study on partially premixed flames in a centerbody burner. Combustion and Flame, 158(3), 511-524. http://doi.org/http://dx.doi.org/10.1016/j.combustflame.2010.09.022

Kazakov, A., Wang, H., \& Frenklach, M. (1995). Detailed modeling of soot formation in laminar premixed ethylene flames at a pressure of 10 bar. Combustion and Flame, $100(1), 111-120$.

Kellerer, H., Koch, R., \& Wittig, S. (2000). Measurements of the growth and coagulation of soot particles in a high-pressure shock tube. Combustion and Flame, 120(1), 188-199.

Khan, I. M., Greeves, G., \& Probert, D. M. (1971). Air pollution control in transport engines. Institution of Mechanical Engineers, 205.

Kitanidis, P. K. (1994). Particle- tracking equations for the solution of the advectiondispersion equation with variable coefficients. Water Resources Research, 30(11), 3225-3227.

Kock, B. F., Tribalet, B., Schulz, C., \& Roth, P. (2006). Two-color time-resolved LII applied to soot particle sizing in the cylinder of a Diesel engine. Combustion and Flame, 147(1), 


\section{ACCEPTED MANUSCRIPT}

79-92.

Kook, S., Zhang, R., Szeto, K., Pickett, L. M., \& Aizawa, T. (2013). In-Flame Soot Sampling and Particle Analysis in a Diesel Engine. SAE International Journal of Fuels and Lubricants, 6(1), 80-97. http://doi.org/10.4271/2013-01-0912

Kuribayashi, M., Ishizuka, Y., \& Aizawa, T. (2013). Sizing of Soot Particles in Diesel Spray Flame-A Qualitative Comparison between TEM Analysis and LII/Scattering Laser Measurements. SAE Technical Paper.

Kuribayashi, M., Mizutani, Y., Ishizuka, Y., Taki, N., \& Aizawa, T. (2014). Effects of ambient oxygen concentration on soot processes in diesel spray flame-A qualitative comparison between TEM analysis and LII/Scattering laser measurements. SAE International Journal of Fuels and Lubricants, 7(3), 693-703.

Lapuerta, M., Ballesteros, R., \& Martos, F. J. (2009). The effect of diesel engine conditions on the size and morphology of soot particles. International Journal of Vehicle Design, 50(1-4), 91-106.

Lapuerta, M., Martos, F. J., \& Herreros, J. M. (2007). Effect of engine operating conditions on the size of primary particles composing diesel soot agglomerates. Journal of Aerosol Science, 38(4), 455-466. http://doi.org/http://dx.doi.org/10.1016/j.jaerosci.2007.02.001

Leung, K. M., Lindstedt, R. P., \& Jones, W. P. (1991). A simplified reaction mechanism for soot formation in nonpremixed flames. Combustion and Flame, 87(3), 289-305.

Lu, T., Cheung, C. S., \& Huang, Z. (2012). Effects of engine operating conditions on the size and nanostructure of diesel particles. Journal of Aerosol Science, 47, 27-38.

Luo, Z., Som, S., Sarathy, S. M., Plomer, M., Pitz, W. J., Longman, D. E., \& Lu, T. (2014). Development and validation of an n-dodecane skeletal mechanism for spray combustion applications. Combustion Theory and Modelling, 18(2), 187-203.

Mahmood, W. M. F. W., LaRocca, A., Shayler, P. J., Bonatesta, F., \& Pegg, I. (2012).

Predicted Paths of Soot Particles in the Cylinders of a Direct Injection Diesel Engine. SAE Technical Paper.

Maraver, A. (2015). Biomass pelletization : standards and production. Southhampton, UK Boston, MA: WIT Press Computational Mechanics International.

Menkiel, B., Donkerbroek, A., Uitz, R., Cracknell, R., \& Ganippa, L. (2012). Measurement 


\section{ACCEPTED MANUSCRIPT}

of in-cylinder soot particles and their distribution in an optical HSDI diesel engine using time resolved laser induced incandescence (TR-LII). Combustion and Flame, 159(9), 2985-2998. http://doi.org/http://dx.doi.org/10.1016/j.combustflame.2012.03.008

Merchan-Merchan, W., Sanmiguel, S. G., \& McCollam, S. (2012). Analysis of soot particles derived from biodiesels and diesel fuel air-flames. Fuel, 102, 525-535.

Mitchell, P., \& Frenklach, M. (1998). Monte Carlo simulation of soot aggregation with simultaneous surface growth-why primary particles appear spherical. Symposium (International) on Combustion, 27(1), 1507-1514.

Moss, J. B., Stewart, C. D., \& Young, K. J. (1995). Modeling soot formation and burnout in a high temperature laminar diffusion flame burning under oxygen-enriched conditions. Combustion and Flame, 101(4), 491-500.

Mueller, M. E., Blanquart, G., \& Pitsch, H. (2009). A joint volume-surface model of soot aggregation with the method of moments. Proceedings of the Combustion Institute, 32(1), 785-792.

Nagle, J., \& Strickland-Constable, R. F. (1962). Oxidation of Carbon between 1000-2000 C. Proceedings of the Fifth Carbon Conference, 1(1), 154.

Naik, C. V, Puduppakkam, K. V, \& Meeks, E. (2014). Simulation of Soot Volume Fraction and Size in High-Pressure Lifted Flames Using Detailed Reaction Mechanisms. ASME Turbo Expo 2014: Turbine Technical Conference and Exposition, V04BT04A025.

Neoh, K. G., Howard, J. B., \& Sarofim, A. F. (1985). Effect of oxidation on the physical structure of soot. Symposium (International) on Combustion, 20(1), 951-957.

Novella, R., García, A., Pastor, J. M., \& Domenech, V. (2011). The role of detailed chemical kinetics on CFD diesel spray ignition and combustion modelling. Mathematical and Computer Modelling, 54(7), 1706-1719.

Omidvarborna, H., Kumar, A., \& Kim, D.-S. (2015). Recent studies on soot modeling for diesel combustion. Renewable and Sustainable Energy Reviews, 48, 635-647. http://doi.org/http://dx.doi.org/10.1016/j.rser.2015.04.019

Pandurangi, S. S., Bolla, M., Wright, Y. M., Boulouchos, K., Skeen, S. A., Manin, J., \& Pickett, L. M. (2016). Onset and Progression of Soot in high-pressure n-Dodecane Sprays under Diesel-Engine Conditions. International Journal of Engine Research, 1468087416661041. 


\section{ACCEPTED MANUSCRIPT}

Pang, K. M., Jangi, M., Bai, X.-S., \& Schramm, J. (2014). Investigation of chemical kinetics on soot formation event of $n$-heptane spray combustion. SAE Technical Paper.

Pang, K. M., Jangi, M., Bai, X.-S., \& Schramm, J. (2015). Evaluation and optimisation of phenomenological multi-step soot model for spray combustion under diesel engine-like operating conditions. Combustion Theory and Modelling, 19(3), 279-308.

Pang, K. M., Ng, H. K., \& Gan, S. (2011). Development of an integrated reduced fuel oxidation and soot precursor formation mechanism for CFD simulations of diesel combustion. Fuel, 90(9), 2902-2914.

Pang, K. M., Ng, H. K., \& Gan, S. (2012a). Investigation of fuel injection pattern on soot formation and oxidation processes in a light-duty diesel engine using integrated CFDreduced chemistry. Fuel, 96, 404-418.

Pang, K. M., Ng, H. K., \& Gan, S. (2012b). Simulation of temporal and spatial soot evolution in an automotive diesel engine using the Moss-Brookes soot model. Energy Conversion and Management, 58, 171-184.

Pang, K. M., Poon, H. M., Ng, H. K., Gan, S., \& Schramm, J. (2015). Soot Formation Modeling of n-dodecane and Diesel Sprays under Engine-Like Conditions. SAE Technical Paper.

Pasternak, M., Mauss, F., \& Bensler, H. (2009). Diesel Engine Cycle Simulation with a Reduced Set of Modeling Parameters Based on Detailed Kinetics. SAE Technical Paper.

Pei, Y., Hawkes, E. R., Kook, S., Goldin, G. M., \& Lu, T. (2015). Modelling n -dodecane spray and combustion with the transported probability density function method. Combustion and Flame, 162(5), 2006-2019. http://doi.org/10.1016/j.combustflame.2014.12.019

Pickett, L. M., \& Siebers, D. L. (2004). Soot in diesel fuel jets: effects of ambient temperature, ambient density, and injection pressure. Combustion and Flame, 138(1-2), 114-135. http://doi.org/http://dx.doi.org/10.1016/j.combustflame.2004.04.006

Piscaglia, F., Onorati, A., Rutland, C. J., \& Foster, D. E. (2009). Multi-dimensional modeling of the soot deposition mechanism in diesel particulate filters. SAE International Journal of Fuels and Lubricants, 1(1), 210-230.

Piscaglia, F., Rutland, C. J., \& Foster, D. E. (2005). Development of a CFD model to study the hydrodynamic characteristics and the soot deposition mechanism on the porous wall 


\section{ACCEPTED MANUSCRIPT}

of a diesel particulate filter. SAE Technical Paper.

Poon, H. M., Pang, K. M., Ng, H. K., Gan, S., \& Schramm, J. (2016). Development of multicomponent diesel surrogate fuel models-Part II: Validation of the integrated mechanisms in 0-D kinetic and 2-D CFD spray combustion simulations. Fuel, 181, 120 130.

Pope, C. J., \& Howard, J. B. (1997). Simultaneous particle and molecule modeling (SPAMM): An approach for combining sectional aerosol equations and elementary gasphase reactions. Aerosol Science and Technology, 27(1), 73-94.

Pope, S. B. (1979). The statistical theory of turbulent flames. Philosophical Transactions of the Royal Society of London A: Mathematical, Physical and Engineering Sciences, 291(1384), 529-568.

Priesching, P., Tatschl, R., Mauss, F., Saric, F., Netzell, K., Bauer, W., ... Vaglieco, B. M. (2005). Soot Particle Size Distribution- A Joint Work for Kinetic Modelling and Experimental Investigations. SAE Technical Paper.

Ranz, W. E., \& Marshall, W. R. (1952). Evaporation from drops. Chemical Engineering Progress, 48(3), 141446.

Ranzi, E., Frassoldati, A., Stagni, A., Pelucchi, M., Cuoci, A., \& Faravelli, T. (2014). Reduced kinetic schemes of complex reaction systems: fossil and biomass- derived transportation fuels. International Journal of Chemical Kinetics, 46(9), 512-542.

Reitz, R. D., \& Diwakar, R. (1986). Effect of drop breakup on fuel sprays. SAE Technical Paper.

Roquemore, W. M., Katta, V., Stouffer, S., Belovich, V., Pawlik, R., Arstingstall, M., ... Roy, S. (2009). Soot studies of laminar diffusion flames with recirculation zones. Proceedings of the Combustion Institute, 32(1), 729-736. http://doi.org/http://dx.doi.org/10.1016/j.proci.2008.06.104

Roy, S. P., Arias, P. G., Lecoustre, V. R., Haworth, D. C., Im, H. G., \& Trouvé, A. (2014). Development of high fidelity soot aerosol dynamics models using method of moments with interpolative closure. Aerosol Science and Technology, 48(4), 379-391.

Ryser, R., Gerber, T., \& Dreier, T. (2009). Soot particle sizing during high-pressure Diesel spray combustion via time-resolved laser-induced incandescence. Combustion and Flame, 156(1), 120-129. 


\section{ACCEPTED MANUSCRIPT}

http://doi.org/http://dx.doi.org/10.1016/j.combustflame.2008.08.005

Saffaripour, M., Veshkini, A., Kholghy, M., \& Thomson, M. J. (2014). Experimental investigation and detailed modeling of soot aggregate formation and size distribution in laminar coflow diffusion flames of Jet A-1, a synthetic kerosene, and n-decane. Combustion and Flame, 161(3), 848-863.

Salenbauch, S., Cuoci, A., Frassoldati, A., Saggese, C., Faravelli, T., \& Hasse, C. (2015). Modeling soot formation in premixed flames using an Extended Conditional Quadrature Method of Moments. Combustion and Flame, 162(6), 2529-2543.

Savic, N., Rahman, M. M., Miljevic, B., Saathoff, H., Naumann, K. H., Leisner, T., ... Ristovski, Z. D. (2016). Influence of biodiesel fuel composition on the morphology and microstructure of particles emitted from diesel engines. Carbon, 104, 179-189.

Singh, J., Balthasar, M., Kraft, M., \& Wagner, W. (2005). Stochastic modeling of soot particle size and age distributions in laminar premixed flames. Proceedings of the Combustion Institute, 30(1), 1457-1465.

Singh, S., Reitz, R. D., \& Musculus, M. P. B. (2005). 2-colorthermometry experiments and high-speed imaging of multi-mode diesel engine combustion. SAE Transactions, 114(4), $1605-1621$.

Skeen, S. A., Manin, J., Pickett, L. M., Cenker, E., Bruneaux, G., Kondo, K., ... Ivarsson, A. (2016). A progress review on soot experiments and modeling in the Engine Combustion Network (ECN). SAE International Journal of Engines, 9(2016-01-0734), 883-898.

Song, J., \& Lee, K. O. (2007). Fuel property impacts on diesel particulate morphology, nanostructures, and NOx emissions. SAE Technical Paper.

Song, Y.-N., \& Zhong, B.-J. (2008). Modeling of soot and polycyclic aromatic hydrocarbons in diesel diffusion combustion. Chemical Engineering \& Technology, 31(10), 1418.

Stiesch, G. (2013). Modeling engine spray and combustion processes. Springer Science \& Business Media.

Tan, S. M., Ng, H. K., \& Gan, S. (2013a). CFD modelling of soot entrainment via thermophoretic deposition and crevice flow in a diesel engine. Journal of Aerosol Science, 66, 83-95. http://doi.org/10.1016/j.jaerosci.2013.08.007

Tan, S. M., Ng, H. K., \& Gan, S. (2013b). Computational study of crevice soot entrainment 


\section{ACCEPTED MANUSCRIPT}

in a diesel engine. Applied Energy, 102, 898-907.

http://doi.org/10.1016/j.apenergy.2012.09.029

Tao, F., Golovitchev, V. I., \& Chomiak, J. (2004). A phenomenological model for the prediction of soot formation in diesel spray combustion. Combustion and Flame, 136(3), 270-282.

Tunér, M., Pasternak, M., Mauss, F., \& Bensler, H. (2008). A PDF-Based Model for Full Cycle Simulation of Direct Injected Engines. SAE Technical Paper.

Turns, S. (2012). An introduction to combustion : concepts and applications. New York: McGraw-Hill.

Vishwanathan, G., \& Reitz, R. D. (2010). Development of a practical soot modeling approach and its application to low-temperature diesel combustion. Combustion Science and Technology, 182(8), 1050-1082.

Vishwanathan, G., \& Reitz, R. D. (2015). Application of a semi-detailed soot modeling approach for conventional and low temperature diesel combustion-Part I: Model performance. Fuel, 139, 757-770.

Wang, B., Mosbach, S., Schmutzhard, S., Shuai, S., Huang, Y., \& Kraft, M. (2016).

Modelling soot formation from wall films in a gasoline direct injection engine using a detailed population balance model. Applied Energy, 163, 154-166.

Wehrfritz, A., Kaario, O., Vuorinen, V., \& Somers, B. (2016). Large Eddy Simulation of n dodecane spray flames using Flamelet Generated Manifolds. Combustion and Flame, 167, 113-131. http://doi.org/10.1016/j.combustflame.2016.02.019

Weller, H. G., Tabor, G., Jasak, H., \& Fureby, C. (1998). A tensorial approach to computational continuum mechanics using object-oriented techniques. Computers in Physics, 12(6), 620-631.

Yamaguchi, T., Kondo, K., Nishigai, H., Takano, S., \& Aizawa, T. (2011). Direct Sampling, TEM analysis and optical measurement of soot particles at different axial locations in a transient spray flame. SAE International Journal of Fuels and Lubricants, 5(2011-012051), 316-328.

Yapp, E. K. Y., Patterson, R. I. A., Akroyd, J., Mosbach, S., Adkins, E. M., Miller, J. H., \& Kraft, M. (2016). Numerical simulation and parametric sensitivity study of optical band gap in a laminar co-flow ethylene diffusion flame. Combustion and Flame, 167, 320- 


\section{ACCEPTED MANUSCRIPT}

334.

Zhang, P., Roberts, R. M., \& Benard, A. (2012). Computational guidelines and an empirical model for particle deposition in curved pipes using an Eulerian-Lagrangian approach. Journal of Aerosol Science, 53, 1-20.

Zhang, Q., Guo, H., Liu, F., Smallwood, G. J., \& Thomson, M. J. (2009). Modeling of soot aggregate formation and size distribution in a laminar ethylene/air coflow diffusion flame with detailed PAH chemistry and an advanced sectional aerosol dynamics model. Proceedings of the Combustion Institute, 32(1), 761-768.

Zhang, R., \& Kook, S. (2014). Influence of Fuel Injection Timing and Pressure on In-Flame Soot Particles in an Automotive-Size Diesel Engine. Environmental Science \& Technology, 48(14), 8243-8250.

Zhang, Z., \& Chen, Q. (2007). Comparison of the Eulerian and Lagrangian methods for predicting particle transport in enclosed spaces. Atmospheric Environment, 41(25), $5236-5248$.

Zhao, B., Yang, Z., Johnston, M. V, Wang, H., Wexler, A. S., Balthasar, M., \& Kraft, M. (2003). Measurement and numerical simulation of soot particle size distribution functions in a laminar premixed ethylene-oxygen-argon flame. Combustion and Flame, 133(1), 173-188.

Zhu, J., Lee, K. O., Yozgatligil, A., \& Choi, M. Y. (2005). Effects of engine operating conditions on morphology, microstructure, and fractal geometry of light-duty diesel engine particulates. Proceedings of the Combustion Institute, 30(2), 2781-2789.

Zuber, M. A., Mahmood, W. M. F. W., Harun, Z., Abidin, Z. Z., La Rocca, A., Shayler, P., \& Bonatesta, F. (2015). Modeling of In-Cylinder Soot Particle Size Evolution and Distribution in a Direct Injection Diesel Engine. SAE Technical Paper. 


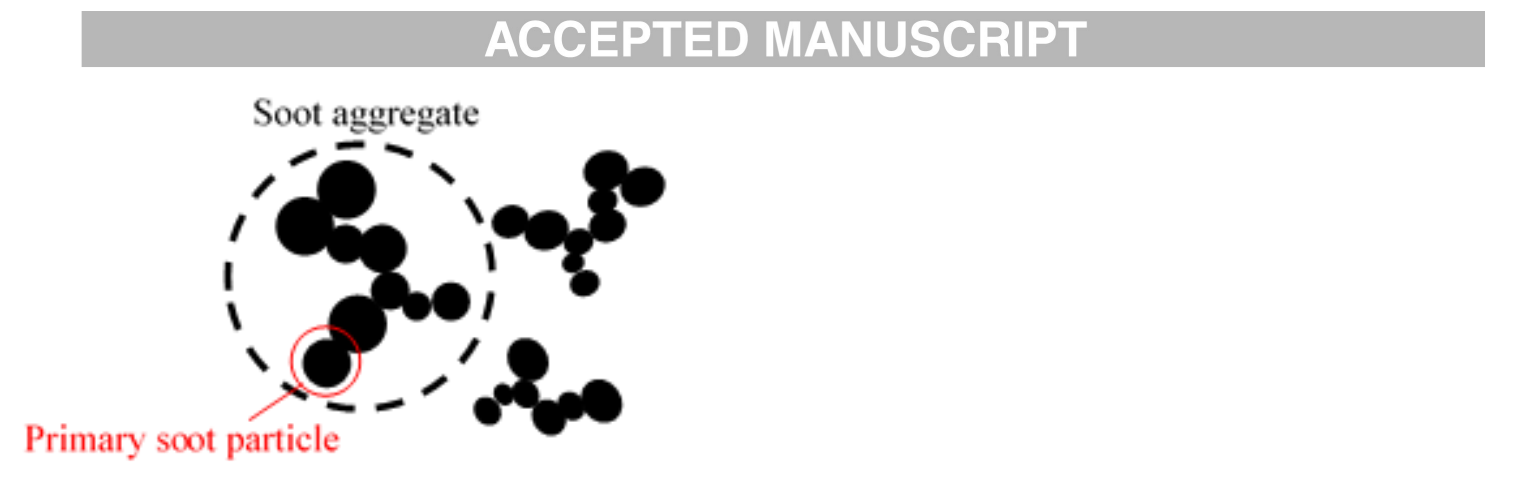

Fig. 1: Soot aggregates made out of primary soot particles (adopted from Kuribayashi, Ishizuka, \& Aizawa (2013)). 


\section{ACCEPTED MANUSCRIPT}

(a)

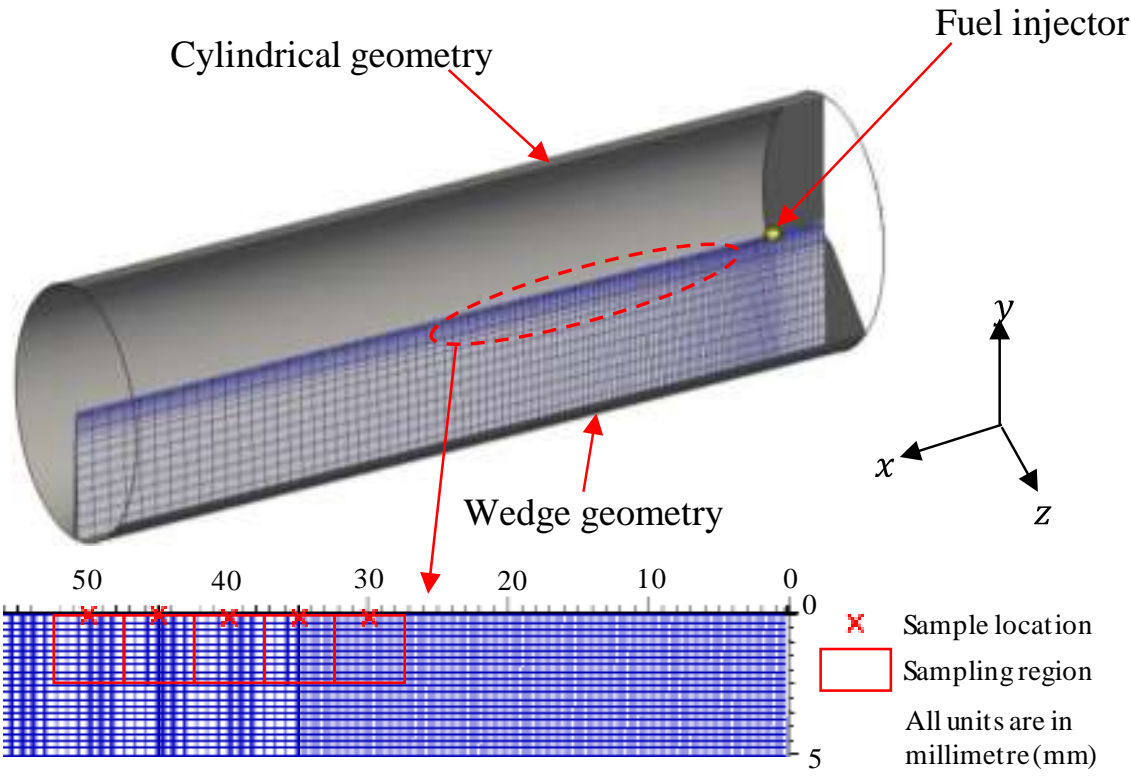

Fig. 2: (a) Computational axisymmetric mesh for constant volume chamber and (b) the sampling region of $\pm 2.5 \mathrm{~mm}$ (radially and axially) about sample location for the LST model. Note that the scales for the radial distance and axial distance are different. 


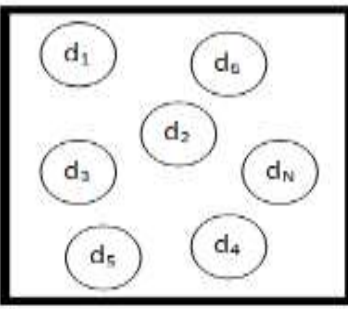

Fig. 3: $N_{p}$ number of soot particles with diameters ranging from $d_{l}$ to $d_{N p}$ in a single computational cell. 


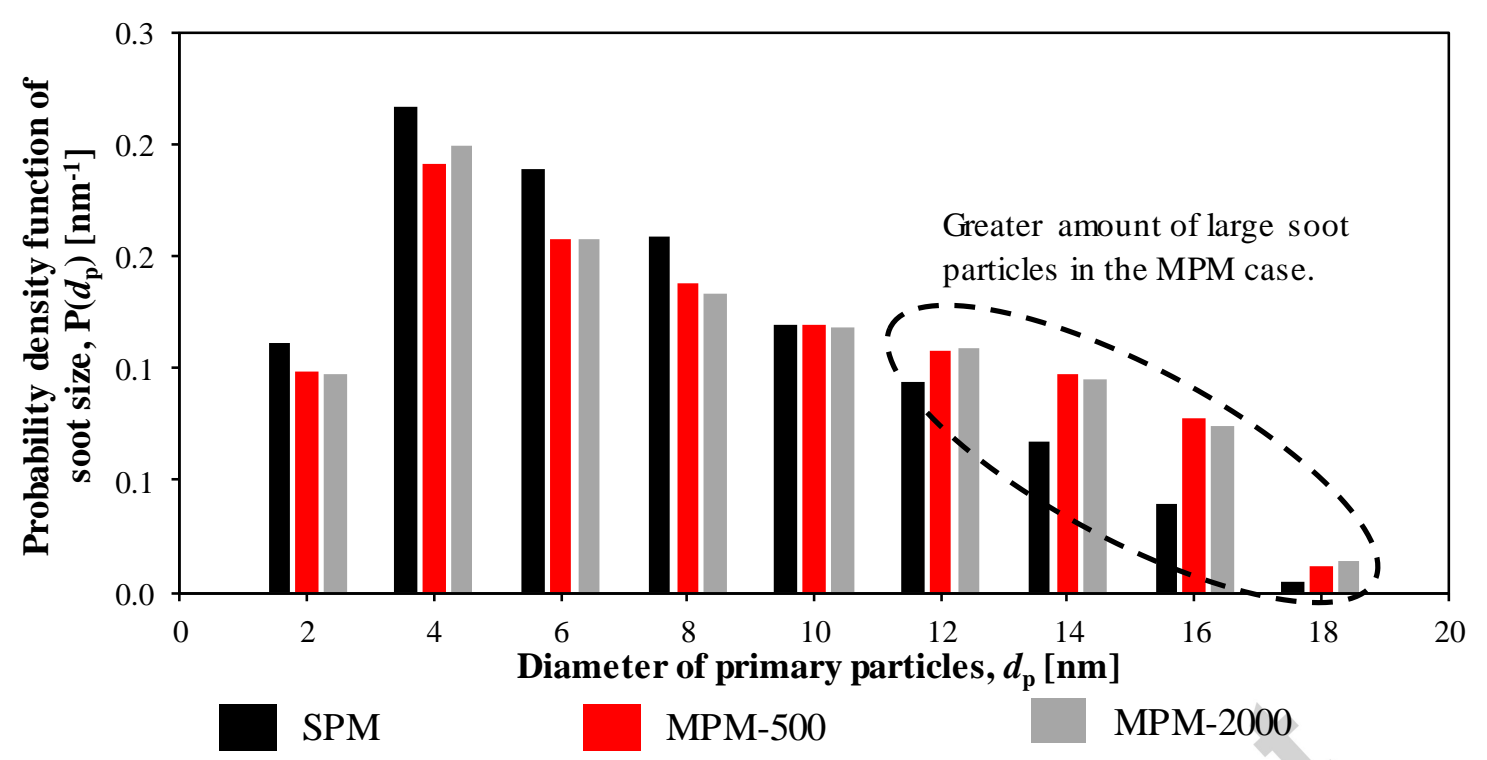

Fig. 4: Primary soot size distribution of the whole soot cloud for the Doshisha $n$-heptane case at $t=1.5 \mathrm{~ms}$ ASOI. 
ACCEPTED MANUSCRIPT

(a) Soot Diameter Distribution

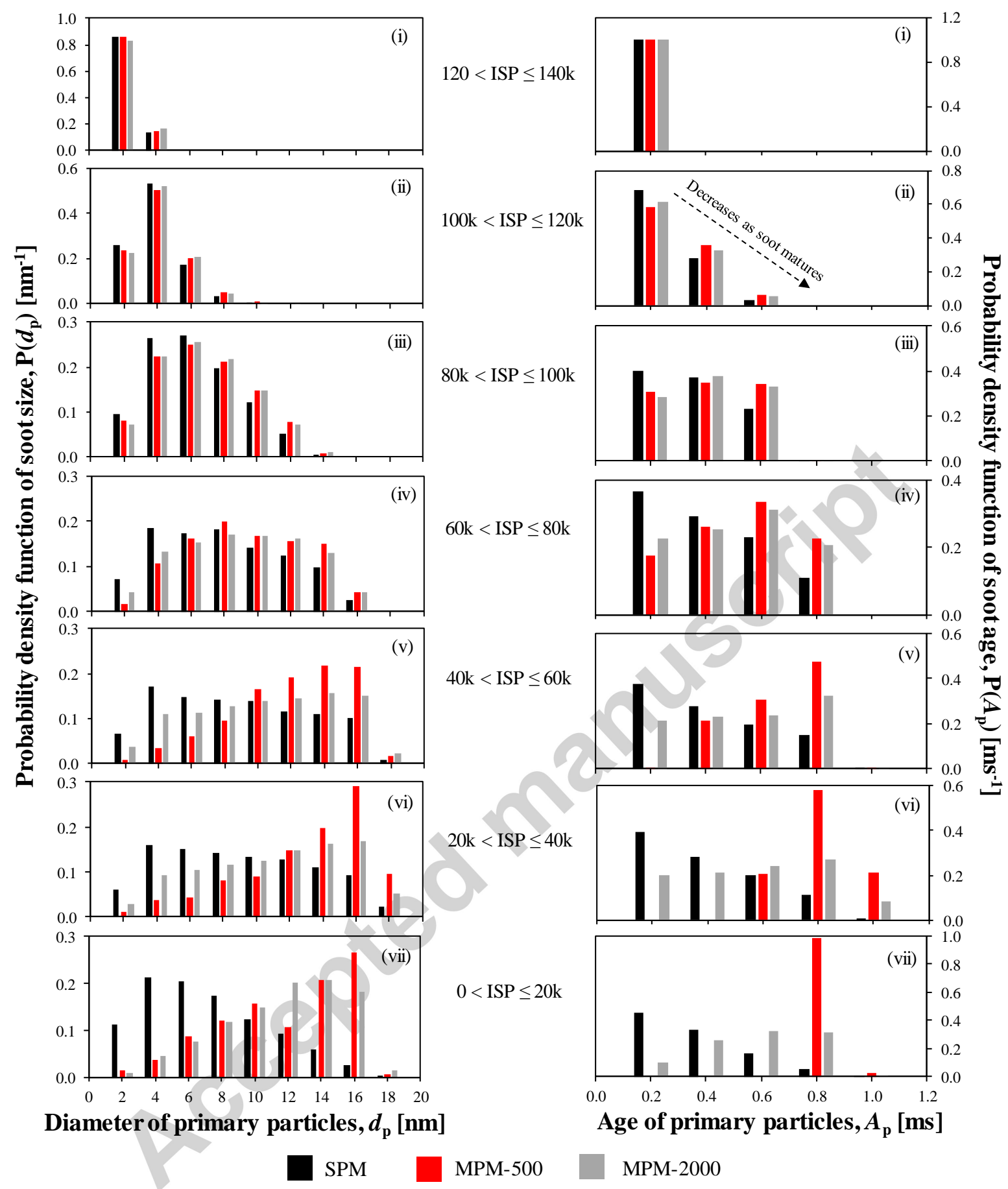

Fig. 5: Primary (a) soot size and (b) soot age distribution at different ISP intervals for the Doshisha $n$-heptane case, $t=1.5 \mathrm{~ms}$ ASOI. 


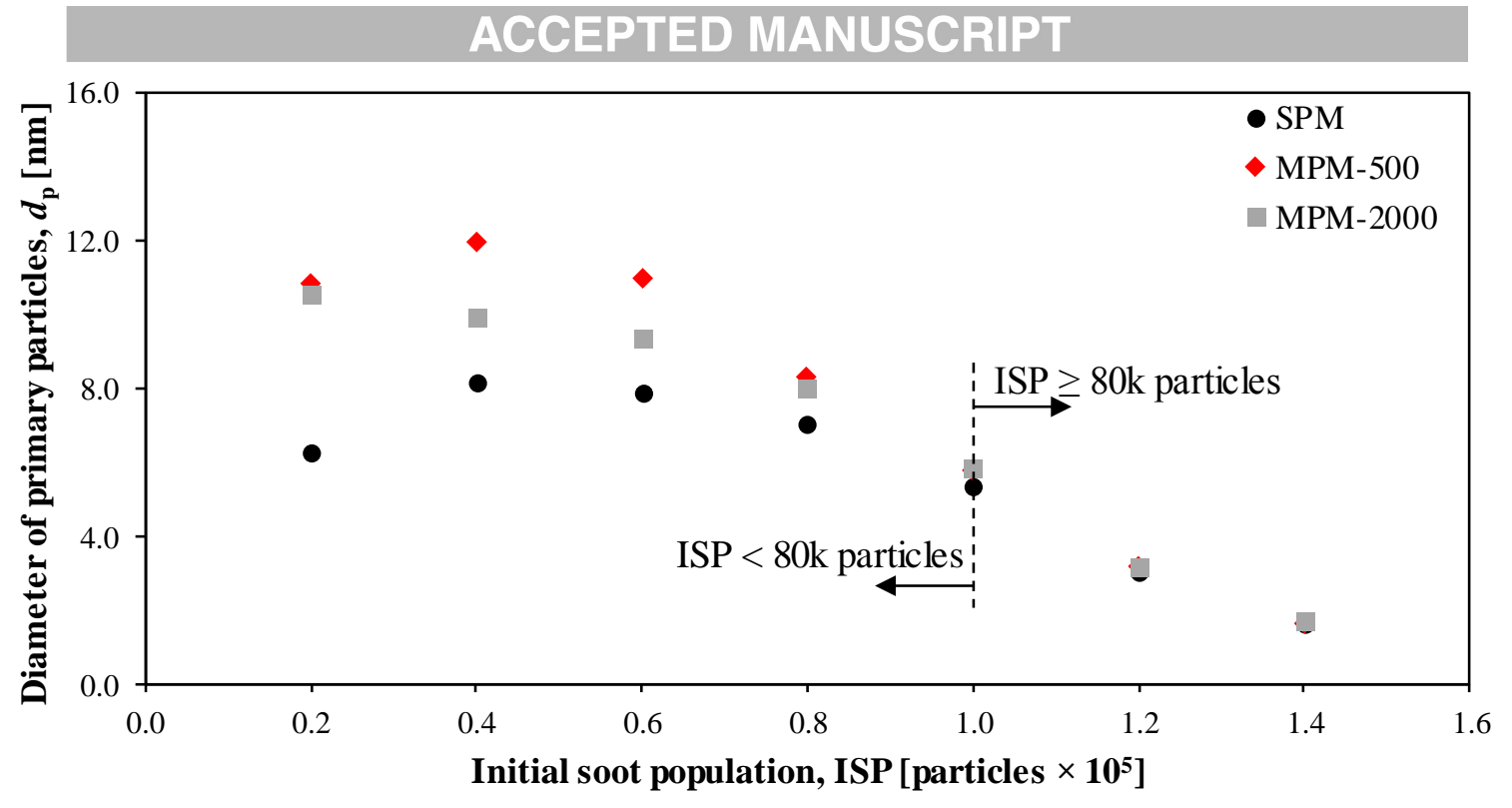

Fig. 6: Mean primary soot diameter predicted by the SPM and MPM at different ISPs for the Doshisha $n$-heptane case, $t=1.5 \mathrm{~ms}$ ASOI. 


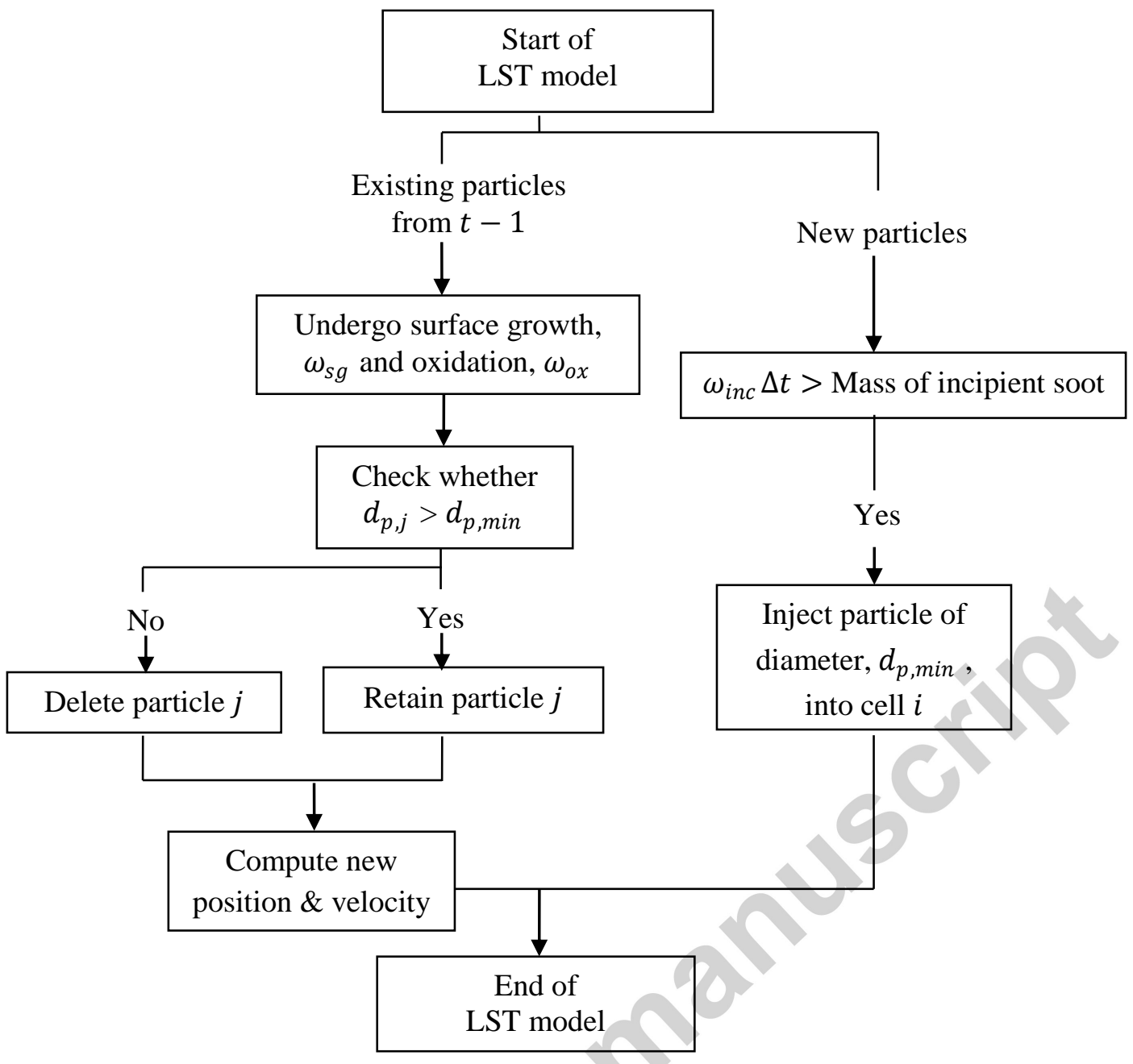

Fig. 7: The step-by-step computation procedure in the proposed LST model. 


\section{ACCEPTED MANUSCRIPT}

(a)

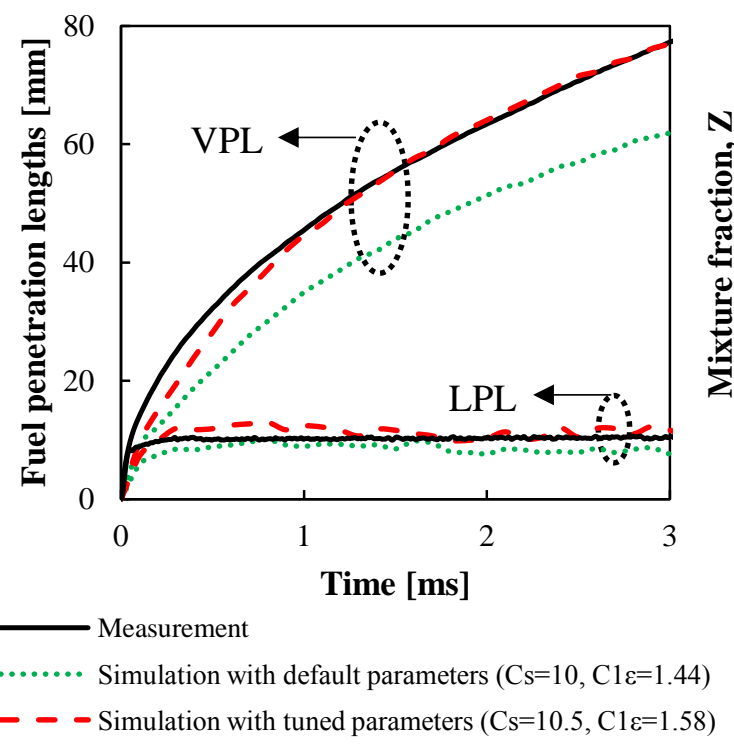

(b)

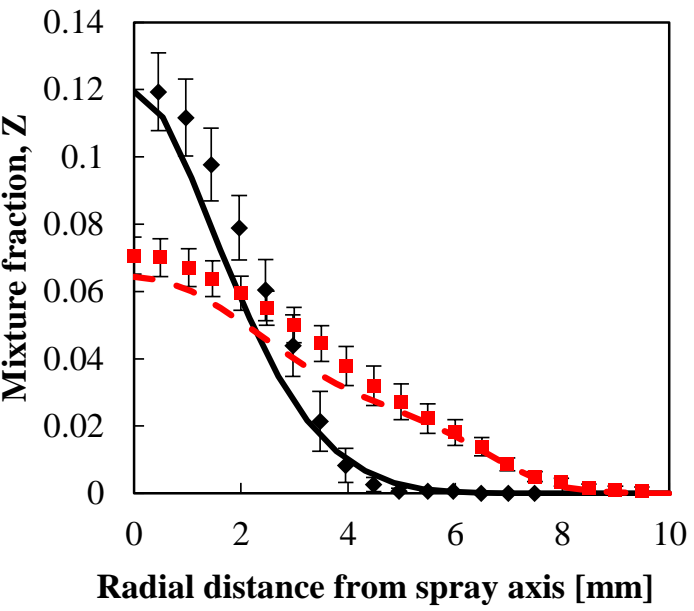

$$
\begin{aligned}
& x=25 \mathrm{~mm} \text { (Measurement) } \\
\mathrm{x} & =45 \mathrm{~mm} \text { (Measurement) } \\
\mathrm{x} & =25 \mathrm{~mm} \text { (Simulation) } \\
\mathrm{x} & =45 \mathrm{~mm} \text { (Simulation) }
\end{aligned}
$$

Fig. 8: (a) Comparison of liquid and vapor penetration length for the non-reacting Sandia $n$ dodecane spray test case (ECN, 2010). (b) Comparison of simulated and experimental radial mixture fraction of the Sandia $n$-dodecane test case at $x=25 \mathrm{~mm}$ and $x=45 \mathrm{~mm}, t=1.5 \mathrm{~ms}$ ASOI. 


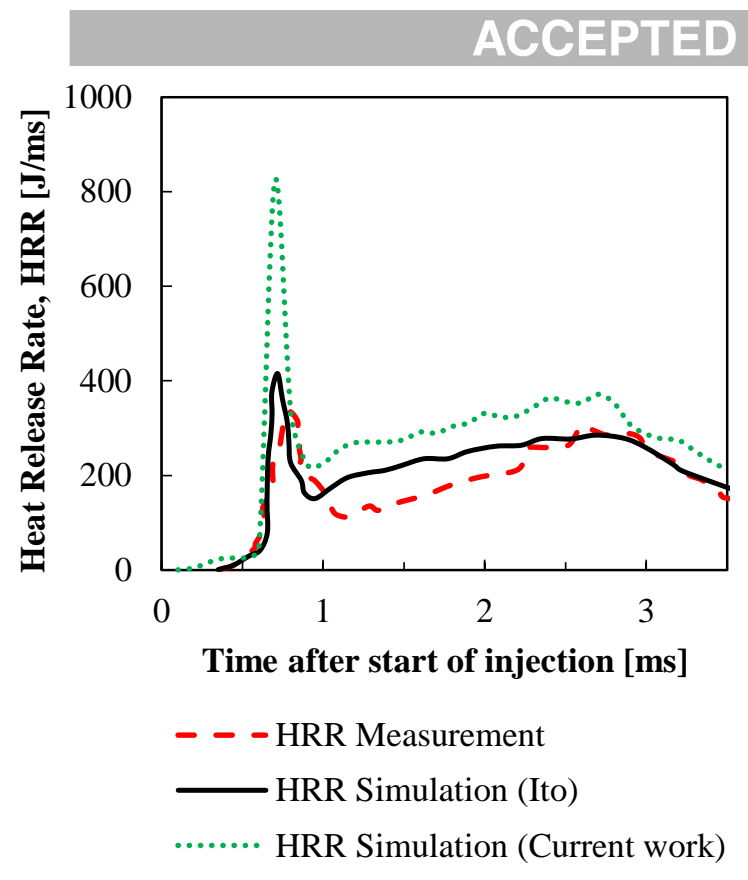

Fig. 9: HRR profile for the reacting Doshisha $n$-heptane spray case at an ambient density of $16.2 \mathrm{~kg} / \mathrm{m}^{3}$, ambient temperature of $900 \mathrm{~K}$ and ambient $\mathrm{O}_{2}$ concentration of $21 \%$ (by volume) (Ito, Hosaka, Ueda, Senda, \& Fujimoto, 2004). 


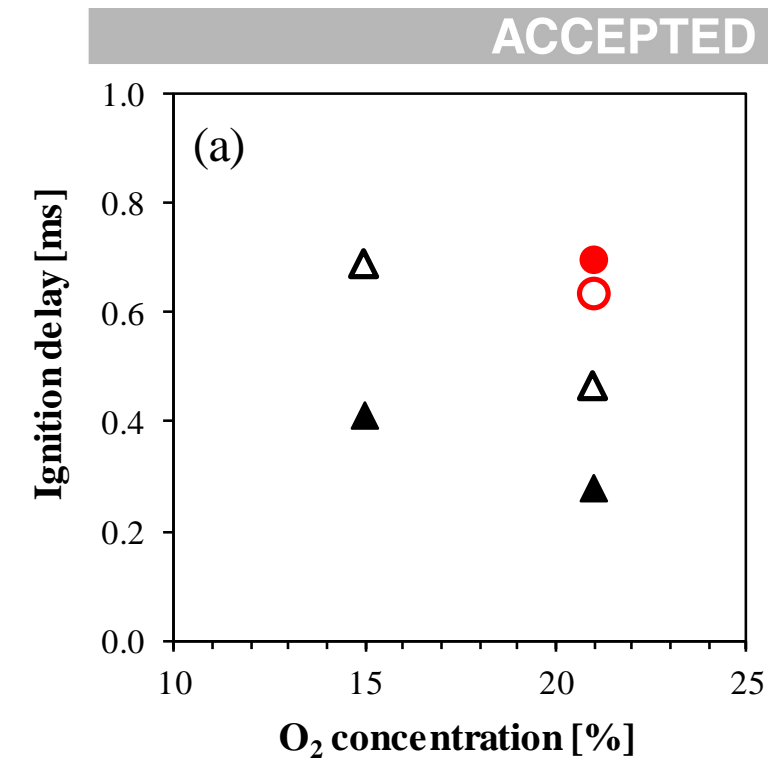

- Doshisha (Measurement) ODoshisha (Simulation)

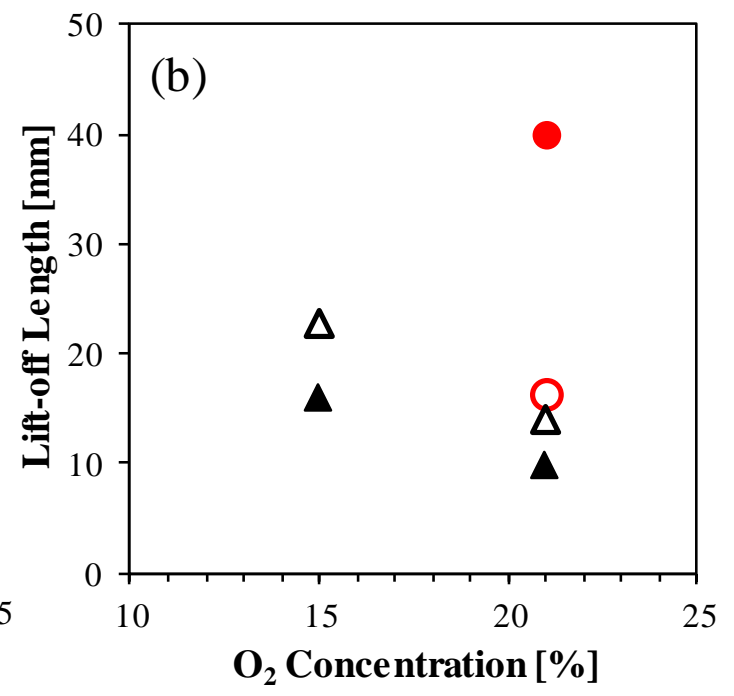

$\Delta$ Sandia n-dodecane (Measurement) $\Delta$ Sandia n-dodecane (Simulation)

Fig. 10: Comparison of simulated (a) ID and (b) LOL for the reacting Doshisha $n$-heptane (Ito, Hosaka, Ueda, Senda, \& Fujimoto, 2004) and the Sandia $n$-dodecane spray case (ECN, 2010) with experimental results. 
(a)

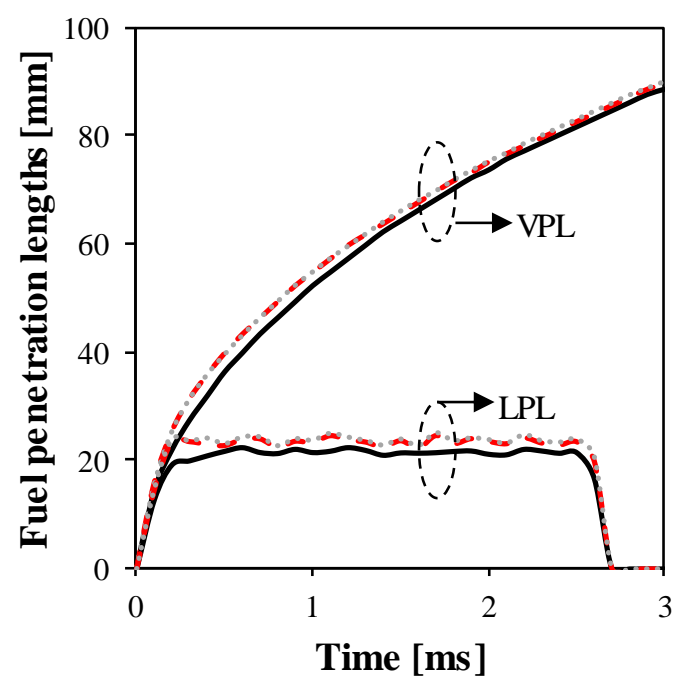

(b)

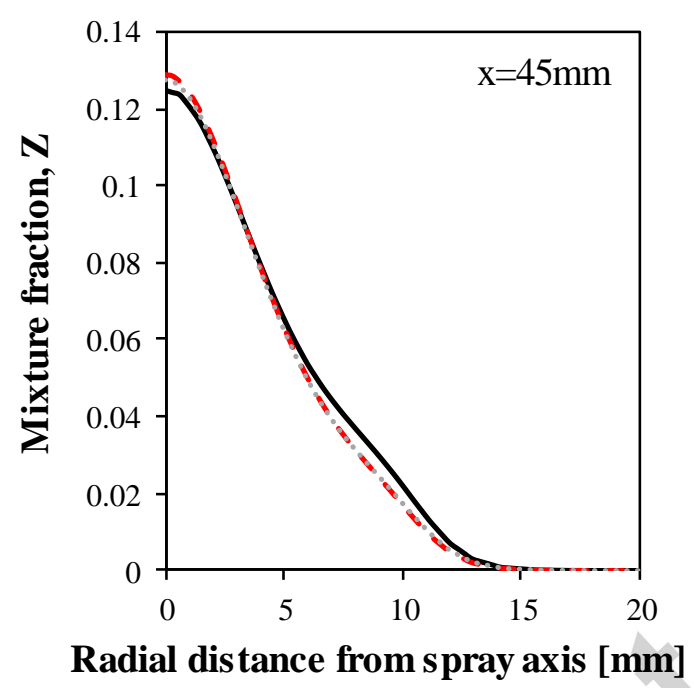

$0.25 \mathrm{~mm} \times 0.25 \mathrm{~mm}$

Fig. 11: (a) Comparison of computed liquid and vapor penetration length for the non-reacting Doshisha $n$-heptane spray test case using different mesh size. (b) Comparison of computed radial mixture fraction of the Doshisha $n$-heptane test case, at $x=45 \mathrm{~mm}$ and $t=1.5 \mathrm{~ms}$ ASOI, using different mesh size. 


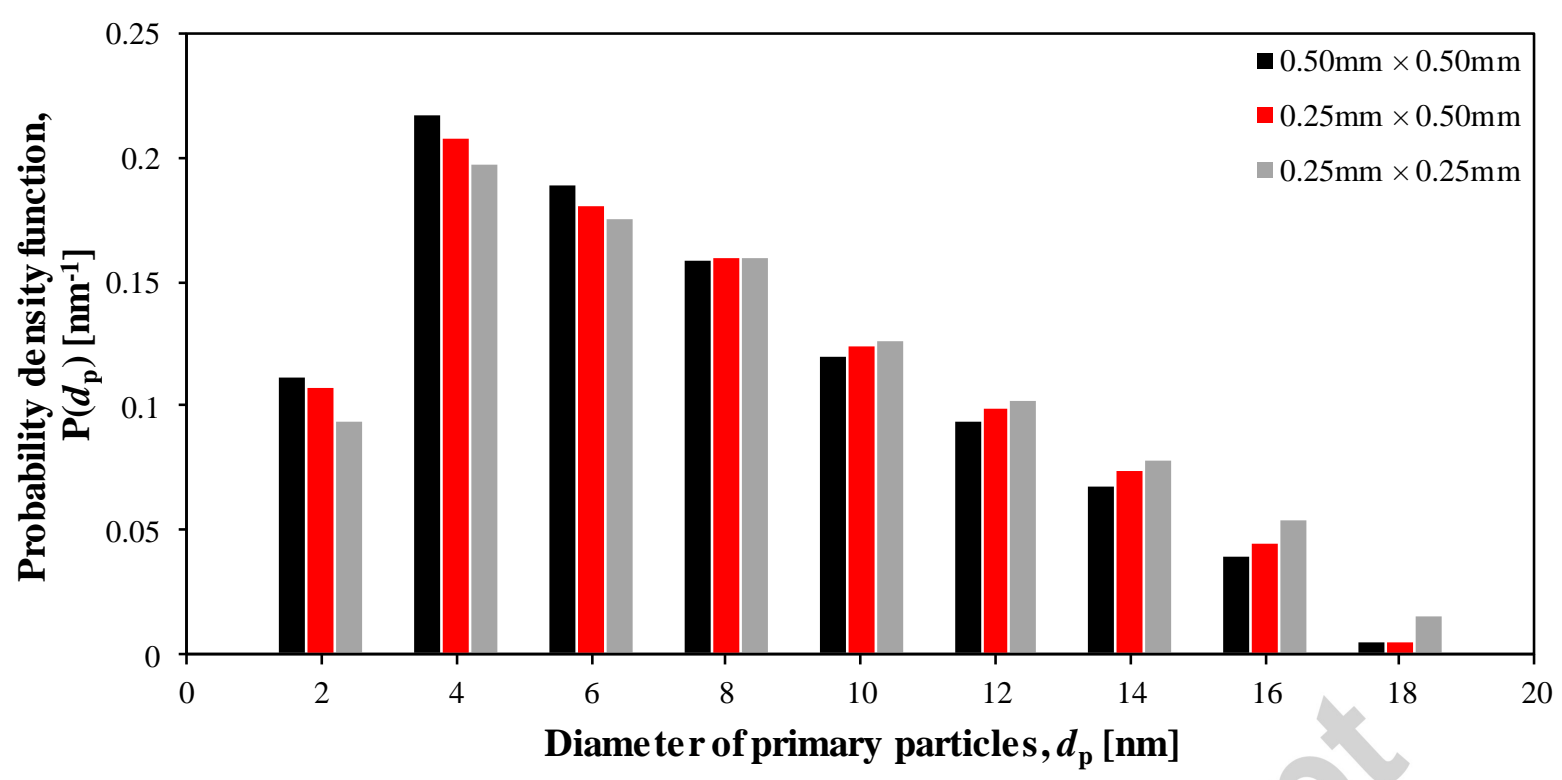

Fig. 12: Convergence test for the LST model in predicting primary soot size distribution in the entire soot cloud for the Doshisha $n$-heptane test case at $t=1.5 \mathrm{~ms}$ ASOI. 


\section{ACCEPTED MANUSCRIPT}

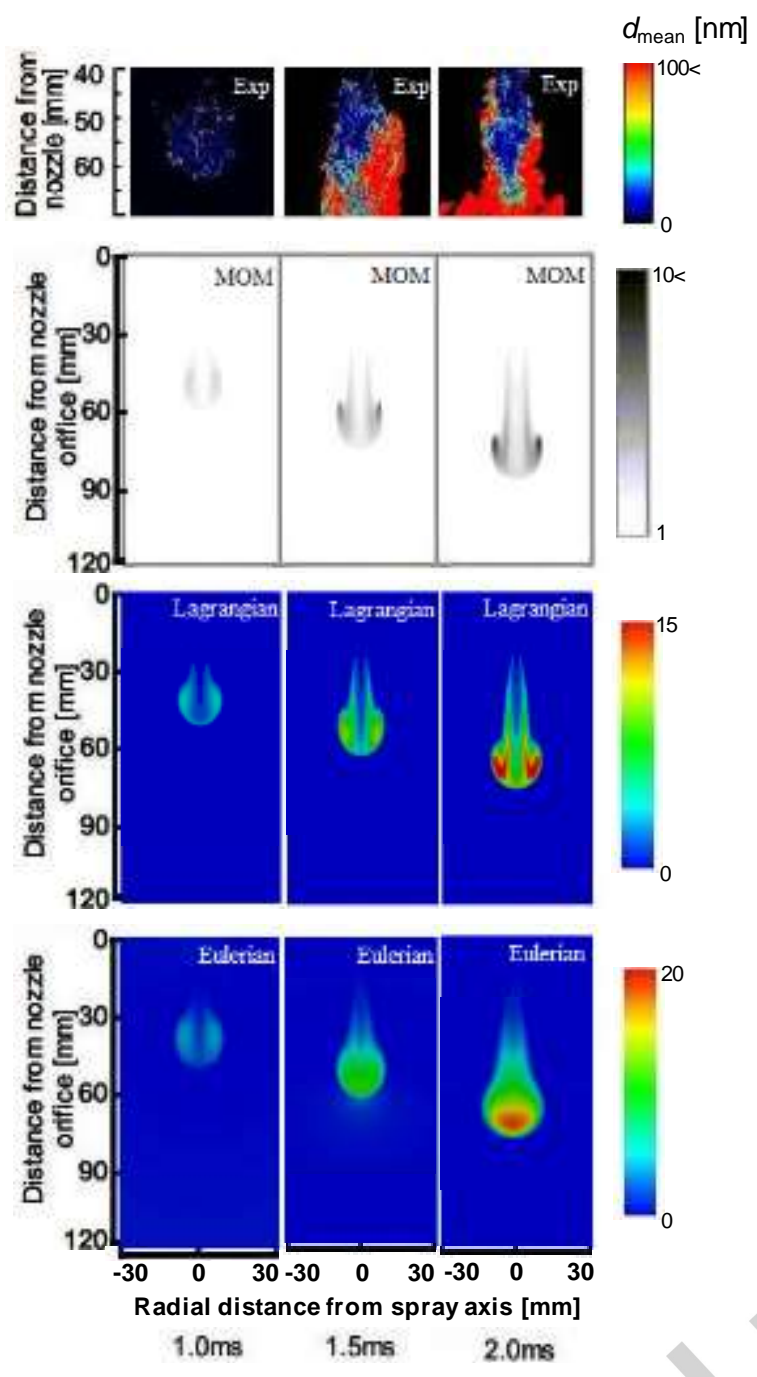

Fig. 13: The mean soot diameter contour compared between experimental (Ito, Hosaka, Ueda, Senda, \& Fujimoto, 2004), MOM simulation (Ito, Hosaka, Ueda, Senda, \& Fujimoto, 2004), Eulerian results and LST results at different time steps from 1.0ms to $2.0 \mathrm{~ms}$ ASOI for the Doshisha $n$-heptane test case (Ito, Hosaka, Ueda, Senda, \& Fujimoto, 2004). 


\section{ACCEPTED MANUSCRIPT}
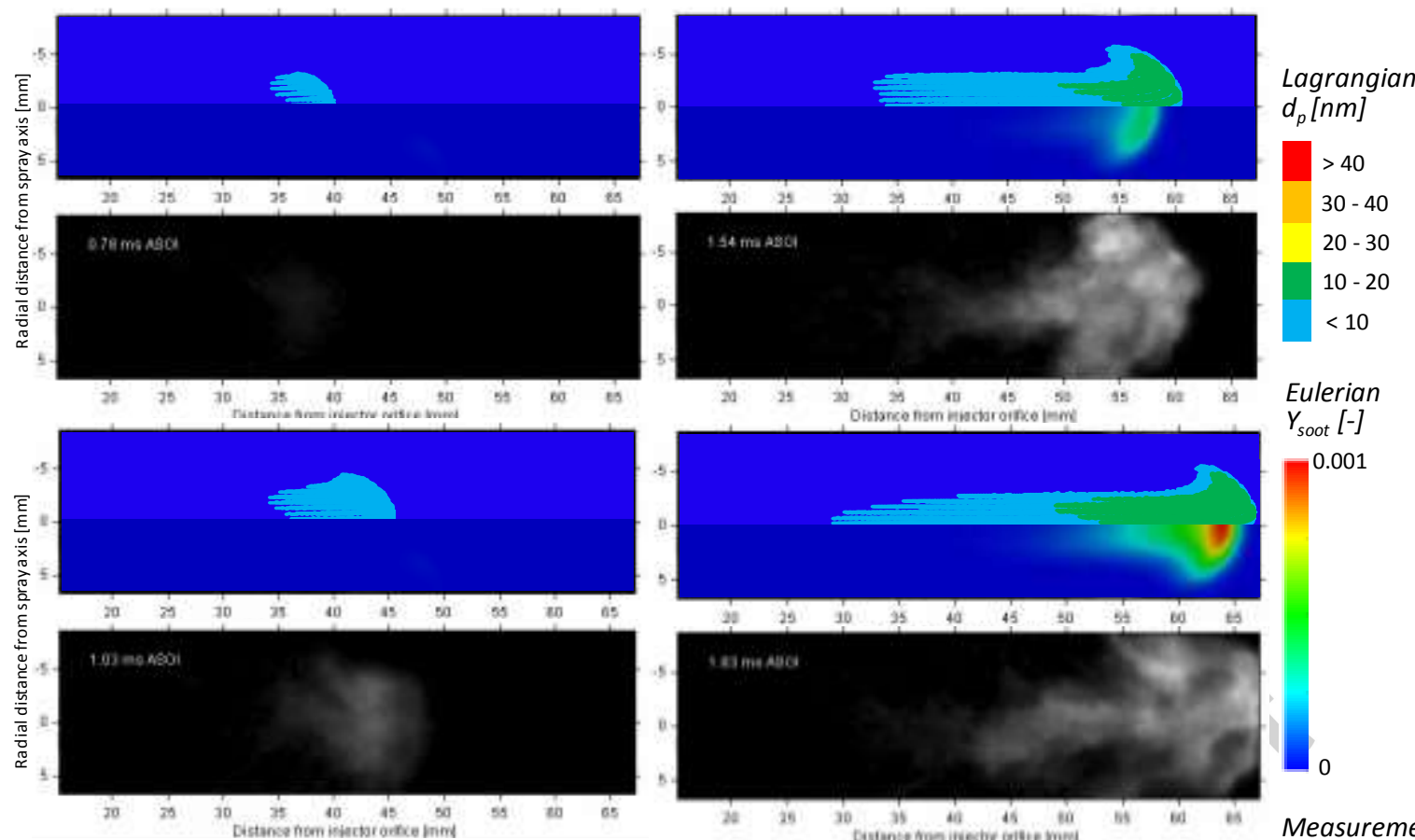

Eulerian

$Y_{\text {soot }}[-]$

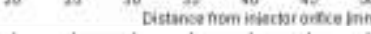
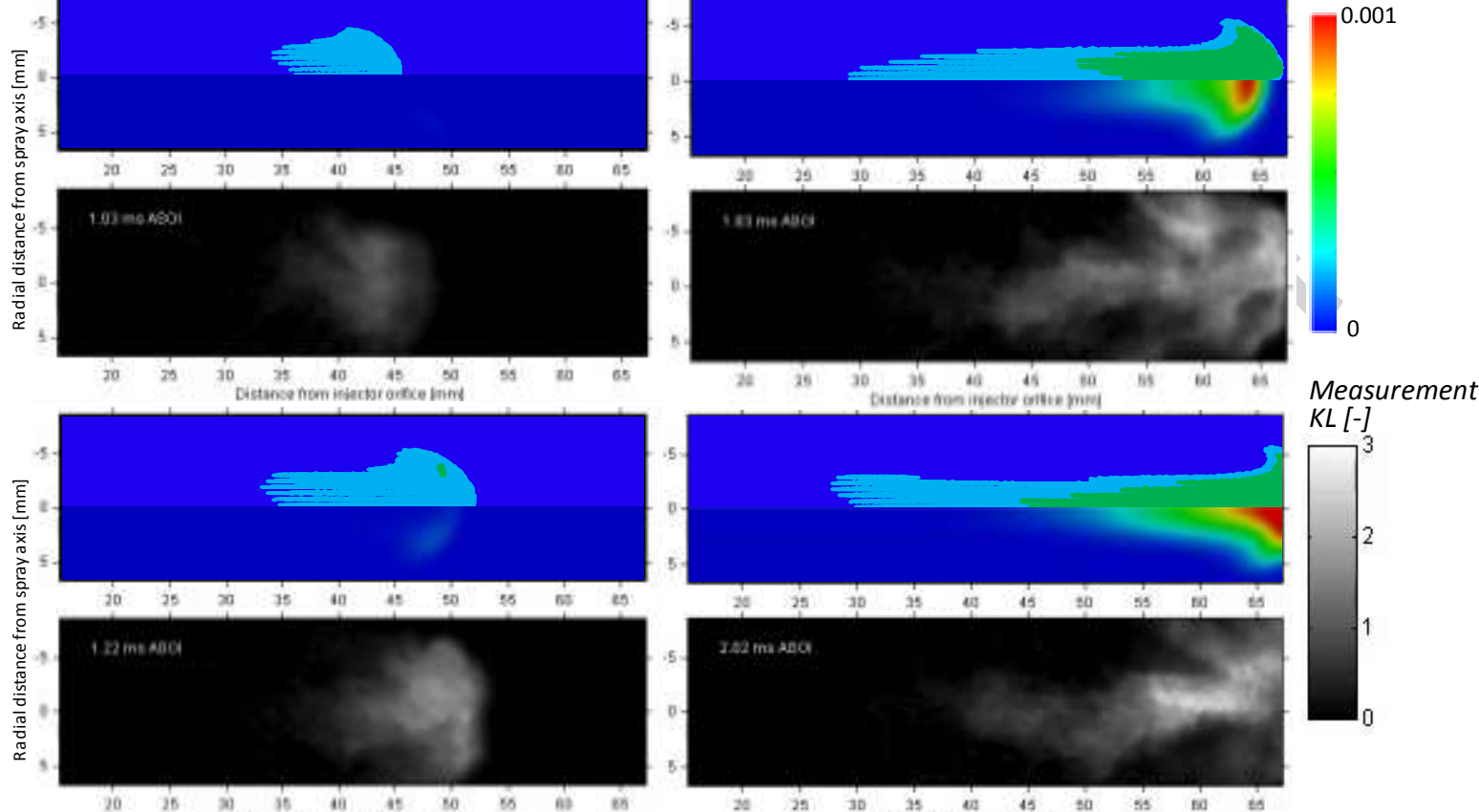

$K L[-]$

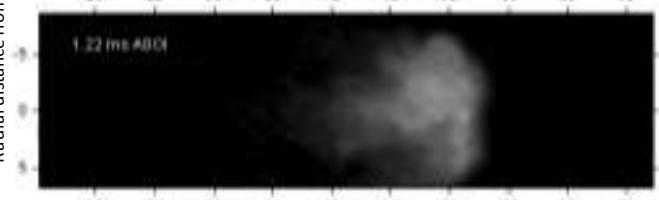

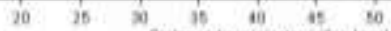

30 is is is in is 30

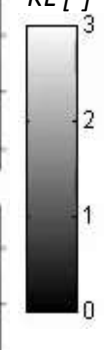

Fig. 14: Comparison of simulated transient primary soot size distribution using LST, Eulerian and experimental soot cloud (ECN, 2010) for the $15 \% \mathrm{O}_{2}$ Sandia $n$-dodecane test cases at an ambient temperature of $900 \mathrm{~K}$ and ambient density of $22.8 \mathrm{~kg} / \mathrm{m}^{3}$. 


\section{ACCEPTED MANUSCRIPT}
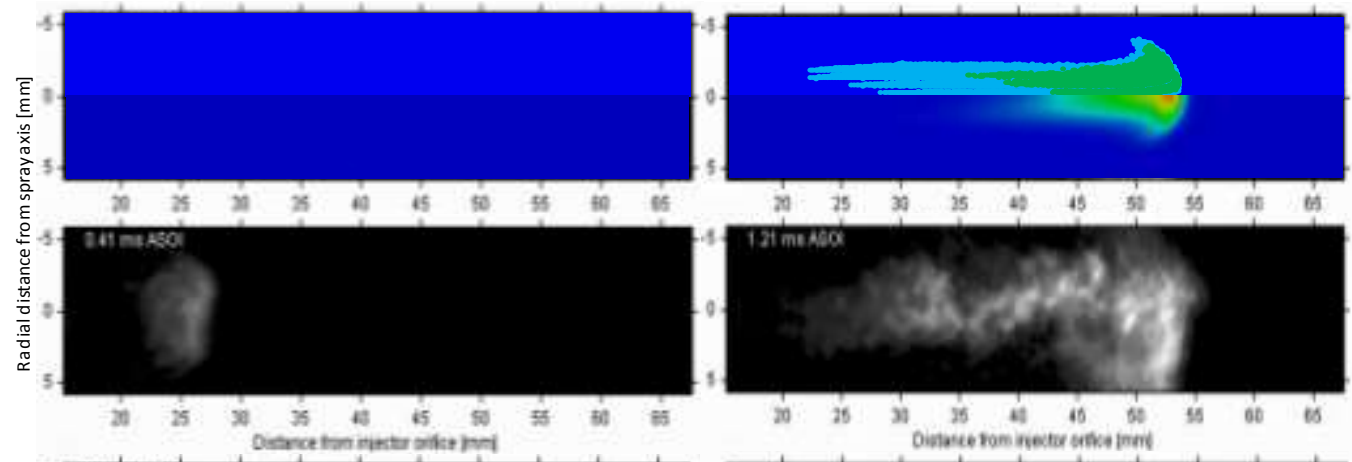

Lagrangian

$d_{p}[n m]$

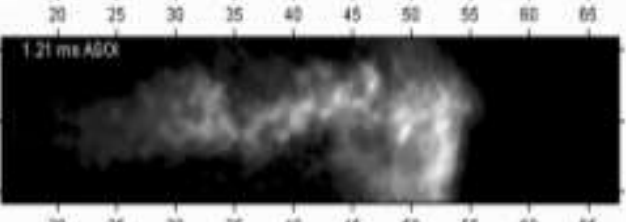

$>40$

$30-40$

$20-30$

$10-20$

$<10$
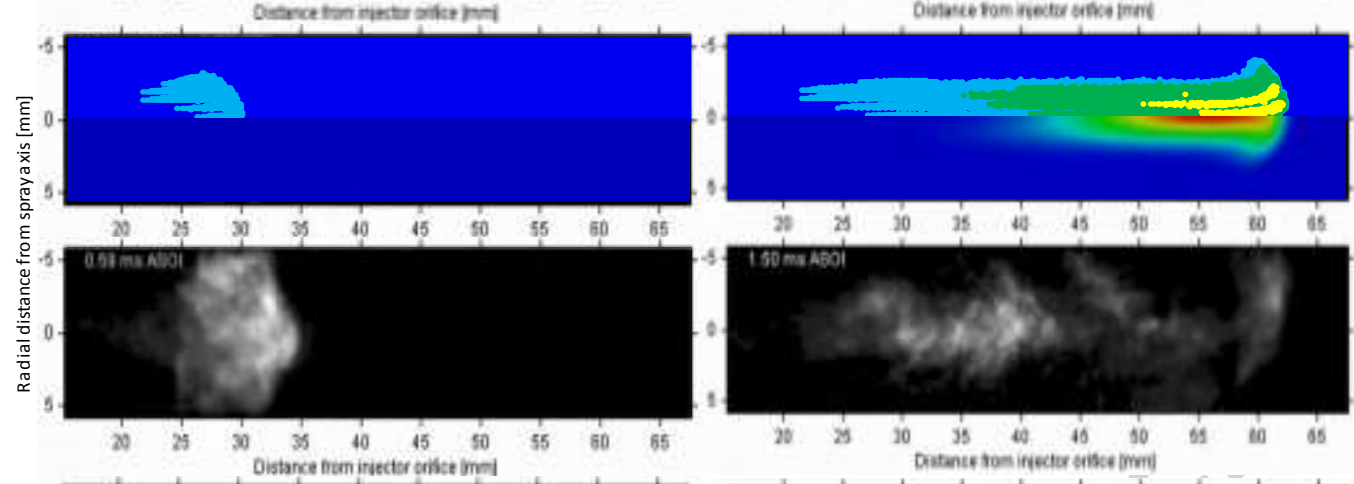

\section{Eulerian}

$Y_{\text {soot }}[-]$
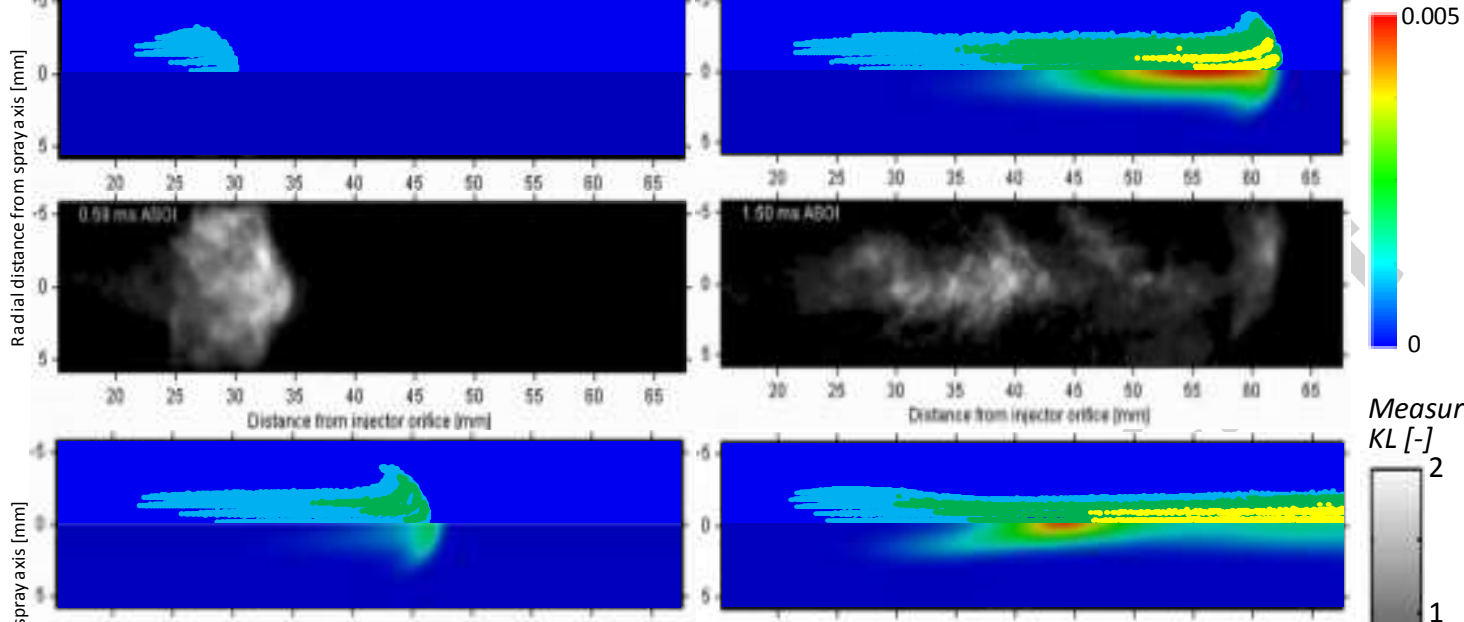

Measurement

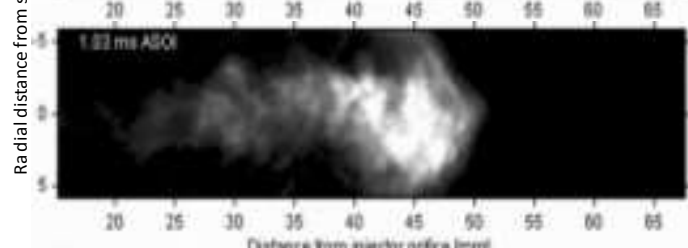

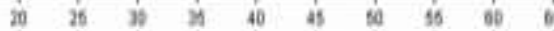

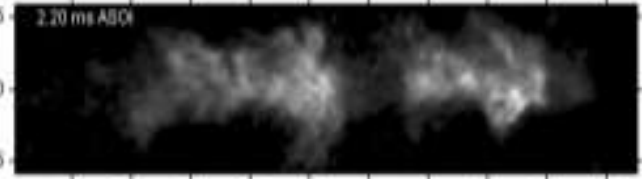

2it 26 is is 40 is is is if 6 $K L[-]$

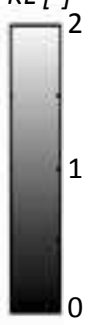

Figure 15: Comparison of simulated transient primary soot size distribution using LST, Eulerian and experimental soot cloud (ECN, 2010) for the $21 \% \mathrm{O}_{2}$ Sandia $n$-dodecane test cases at an ambient temperature of $900 \mathrm{~K}$ and ambient density of $22.8 \mathrm{~kg} / \mathrm{m}^{3}$. 


\section{ACCEPTED MANUSCRIPT}

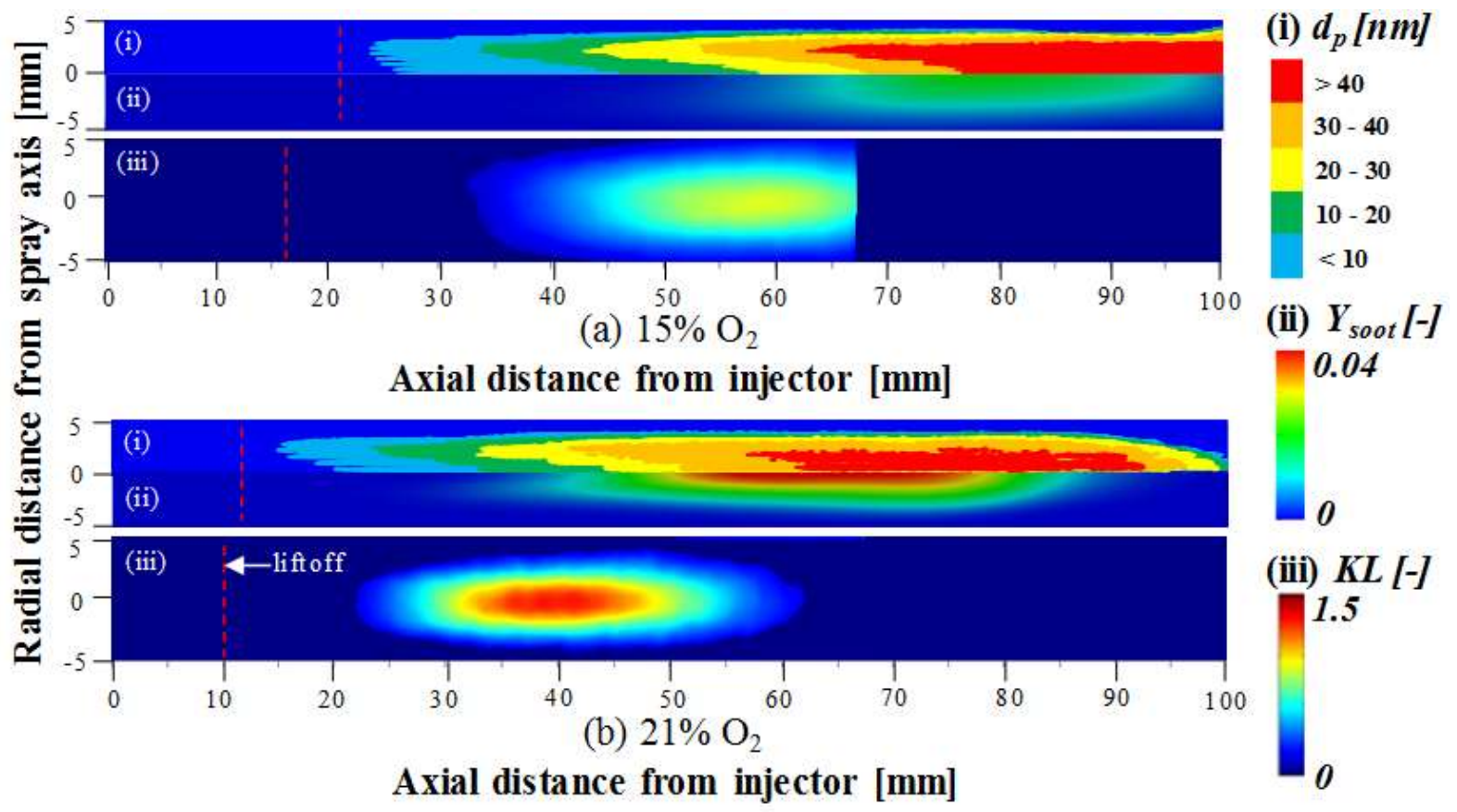

Fig. 16: Comparison of quasi steady-state (i) primary soot size distribution via LST and (ii) experimental SVF results (ECN, 2010) for the (a) $15 \%$ and (b) $21 \% \mathrm{O}_{2}$ Sandia $n$-dodecane test cases at an ambient temperature of $900 \mathrm{~K}$ and ambient density of $22.8 \mathrm{~kg} / \mathrm{m}^{3}$. [Note: The lift-off length is indicated by the red-dashed line] 


\section{ACCEPTED MANUSCRIPT}

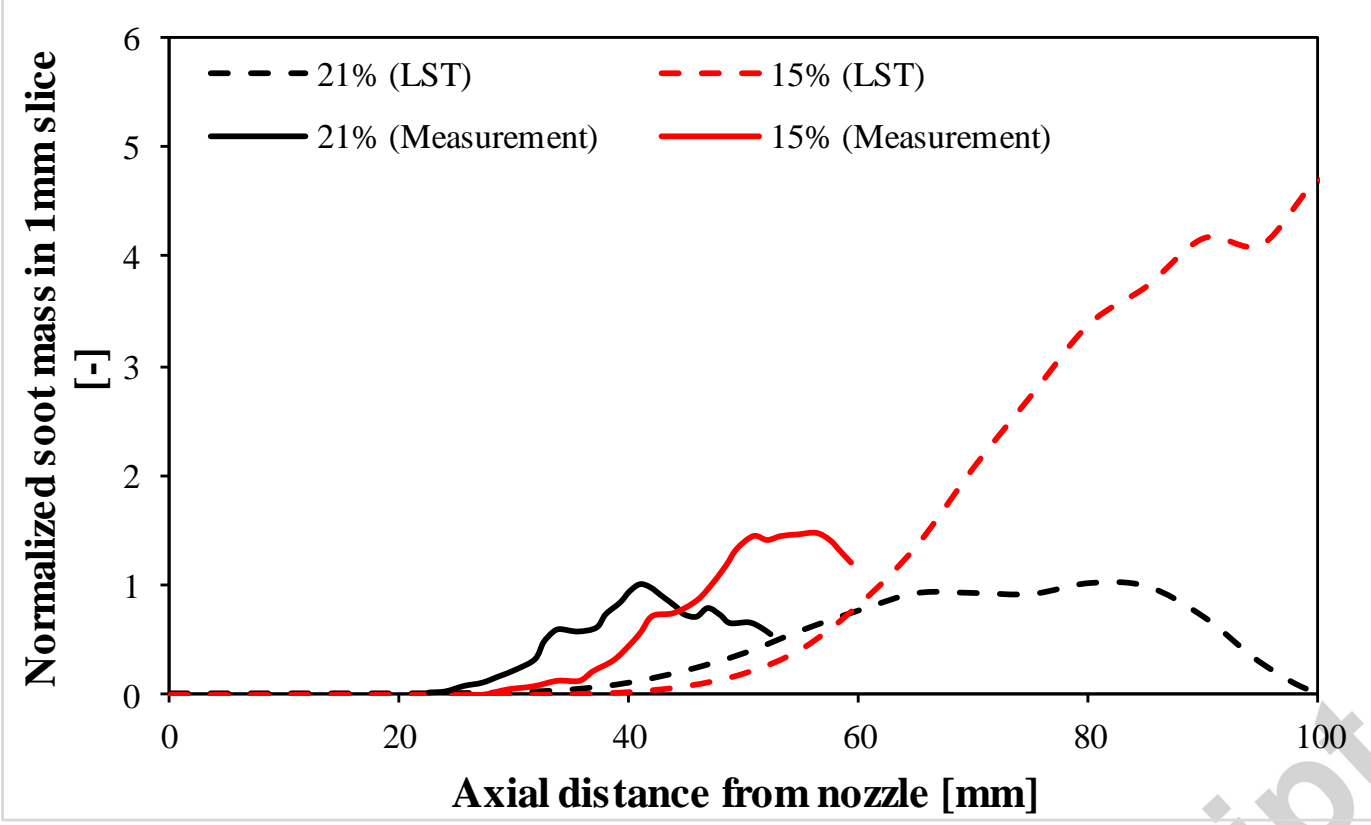

Figure 17: Soot mass for in thin $(1 \mathrm{~mm})$ cross-sections of the jet as a function of axial distance. 


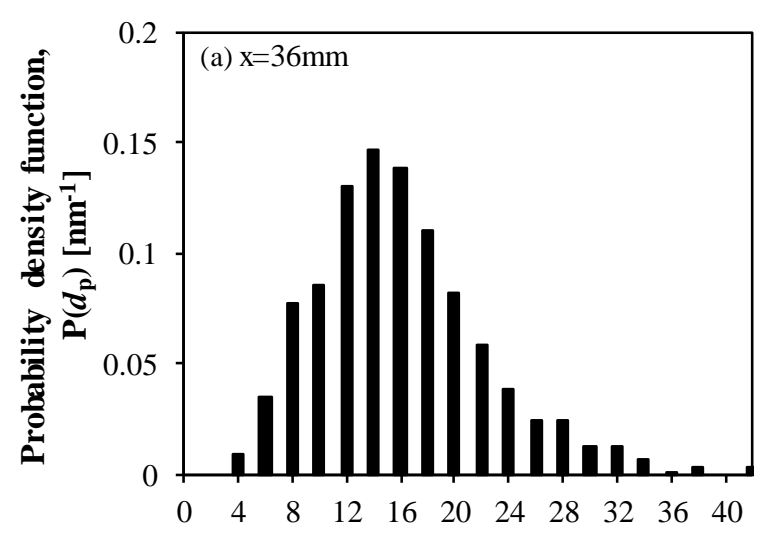

Diameter of primary particles, $d_{\mathrm{p}}[\mathrm{nm}]$
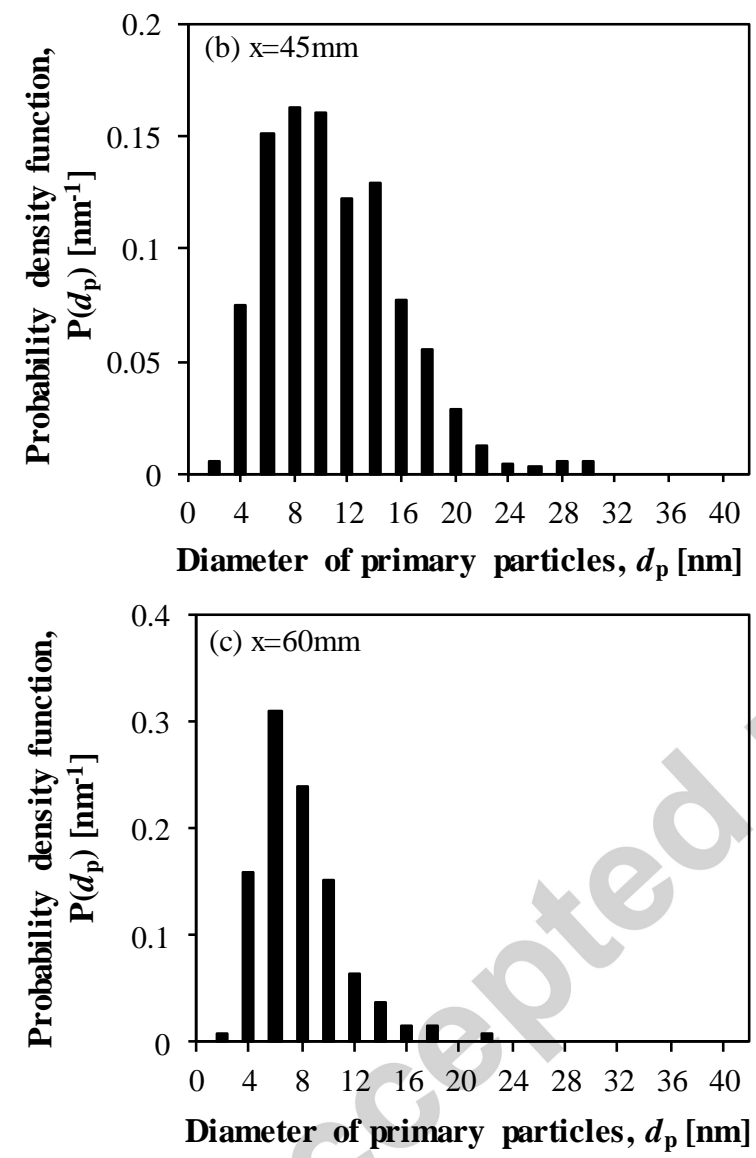

Fig. 18: Experimental primary soot size distribution at (a) $x=36 \mathrm{~mm}$, (b) $x=45 \mathrm{~mm}$ and (c) $x=60 \mathrm{~mm}$ from injector for the $21 \% \mathrm{O}_{2}$ Sandia $n$-dodecane test case at an ambient temperature of $900 \mathrm{~K}$ and ambient density of $22.8 \mathrm{~kg} / \mathrm{m}^{3}$ (redrawn from Cenker, Gilles, \& Christof, (2014)). 

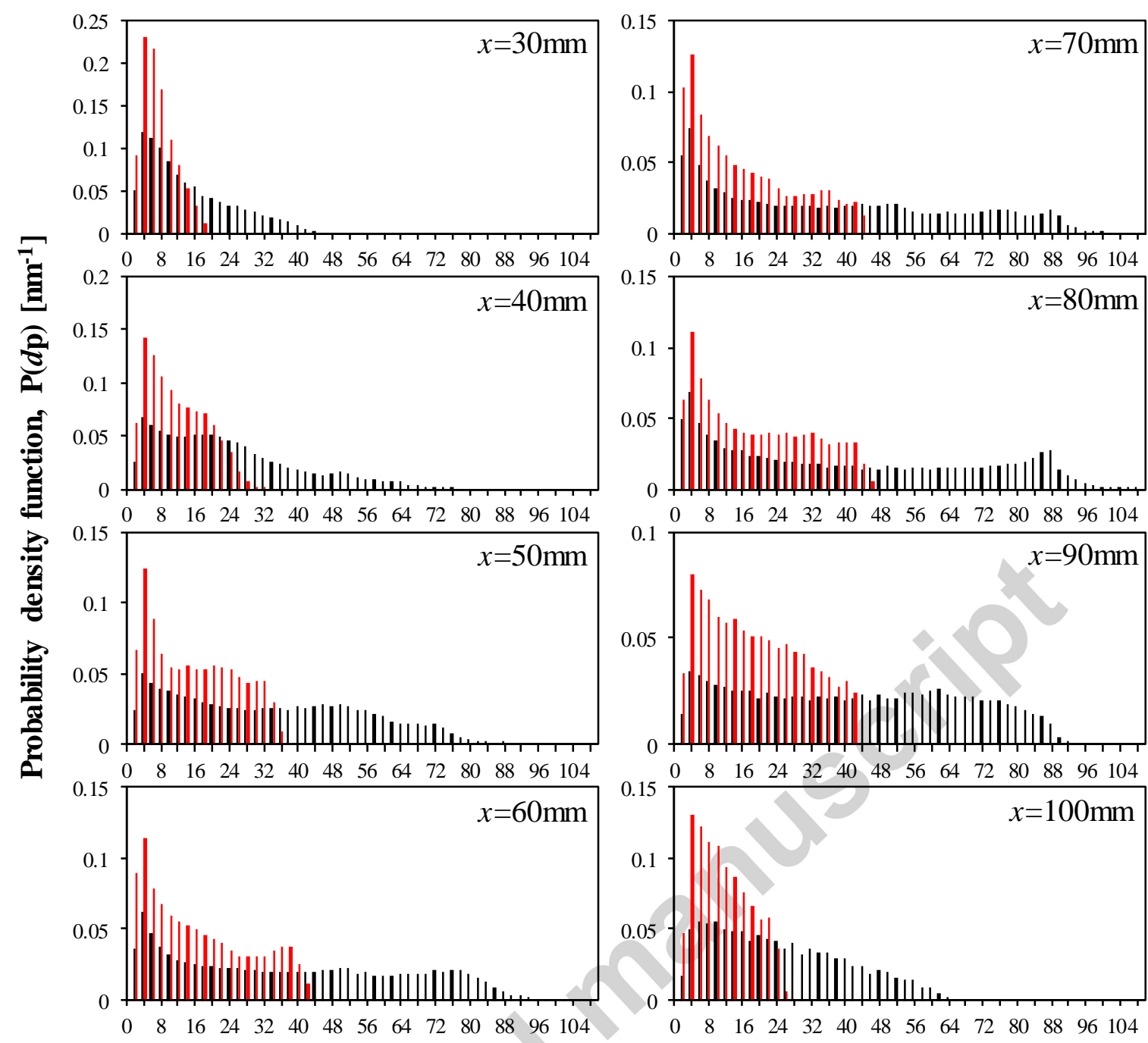

Diameter of primary particles, $d_{\mathrm{p}}[\mathrm{nm}]$
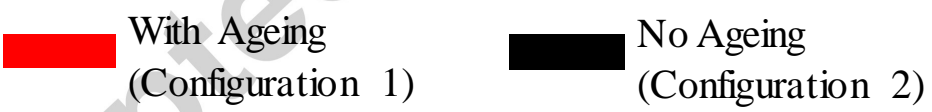

Fig. 19: Comparison of primary soot size distribution at $x=30 \mathrm{~mm}$ to $100 \mathrm{~mm}$ from the injector location, with an interval of $10 \mathrm{~mm}$, between configurations 1 and 2 for the $21 \% \mathrm{O}_{2}$ Sandia $n$ dodecane test case at an ambient temperature of $900 \mathrm{~K}$ and ambient density of $22.8 \mathrm{~kg} / \mathrm{m}^{3}$. 

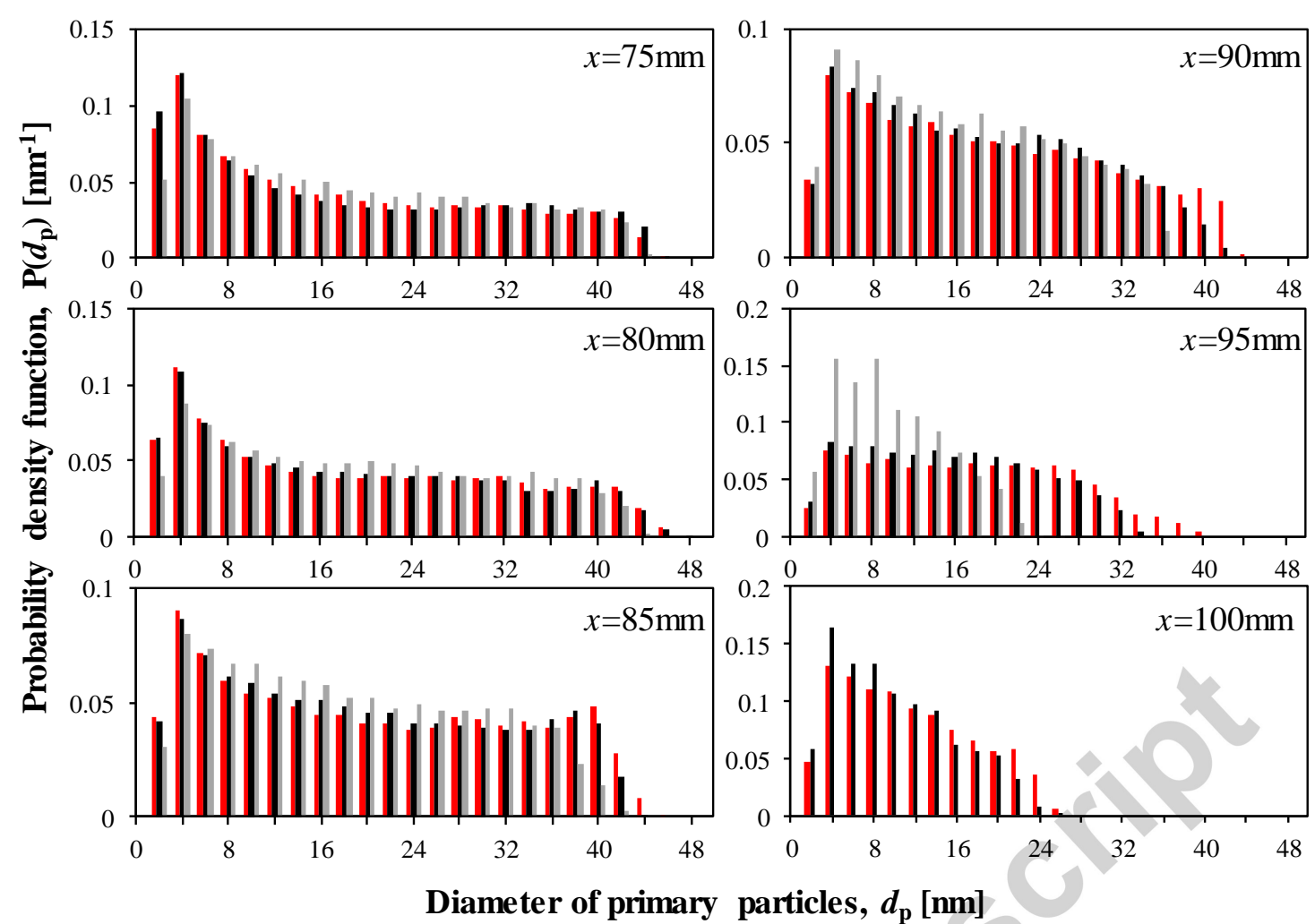

Configuration 1

Diameter of primary particles, $d_{\mathrm{p}}[\mathrm{nm}]$

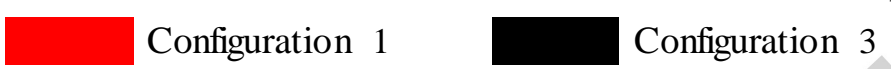

Configuration 4

Fig. 20: Comparison of primary soot size distribution at $x=75 \mathrm{~mm}$ to $100 \mathrm{~mm}$ from injector location, with an interval of $5 \mathrm{~mm}$, between configurations 1,3 and 4 for the $21 \% \mathrm{O}_{2}$ Sandia $n$-dodecane test case at an ambient temperature of $900 \mathrm{~K}$ and ambient density of $22.8 \mathrm{~kg} / \mathrm{m}^{3}$. 

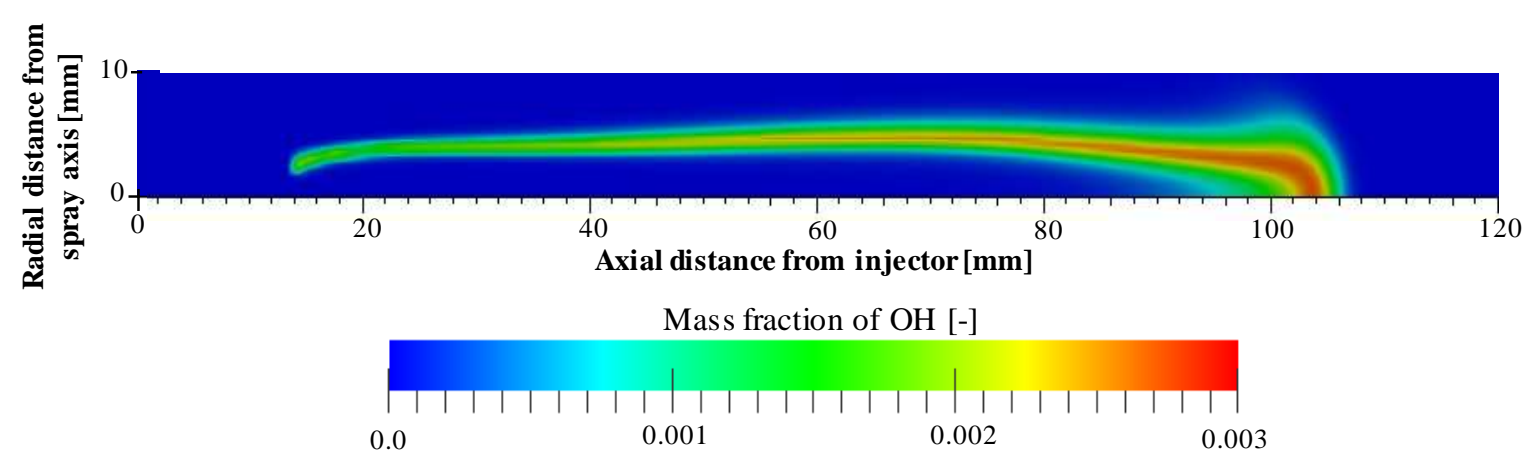

Fig. 21: The predicted $\mathrm{OH}$ distribution at quasi-steady state for the $21 \% \mathrm{O}_{2}$ Sandia $n$ dodecane test case at an ambient temperature of $900 \mathrm{~K}$ and ambient density of $22.8 \mathrm{~kg} / \mathrm{m}^{3}$.

\section{Highlights}

- A Lagrangian Soot Tracking model is implemented to model primary soot size.

- The model considers nucleation, surface growth and oxidation mechanisms.

- The model can capture the soot cloud distribution and the soot size distribution.

- The model allows the accessibility to individual soot particle information.

- Surface ageing has significant effect on the primary soot size predicted. 